\title{
ATMOSPHERIC DISPERSION ESTIMATES IN THE VICINITY OF BUILDINGS
}

J. V. Ramsdell, Jr.

C. J. Fosmire

January 1995

Prepared for the

Division of Radiation Safety and Safeguards

Office of Nuclear Reactor Regulation

U.S. Nuclear Regulatory Commission

and the U.S. Department of Energy

under Contract DE-AC06-76RLO 1830

Pacific Northwest Laboratory

Richland, Washington 99352 



\section{DISCLAIMER}

This report was prepared as an account of work sponsored by an agency of the United States Government. Neither the United States Government nor any agency thereof, nor any of their employees, make any warranty, express or implied, or assumes any legal liability or responsibility for the accuracy, completeness, or usefulness of any information, apparatus, product, or process disclosed, or represents that its use would not infringe privately owned rights. Reference herein to any specific commercial product, process, or service by trade name, trademark, manufacturer, or otherwise does not necessarily constitute or imply its endorsement, recommendation, or favoring by the United States Government or any agency thereof. The views and opinions of authors expressed herein do not necessarily state or reflect those of the United States Government or any agency thereof. 


\section{DISCLAIMER}

Portions of this document may be illegible in electronic image products. Images are produced from the best available original document. 


\begin{abstract}
A model describing atmospheric dispersion in the vicinity of buildings was developed for the U.S. Nuclear Regulatory Commission (NRC) in the late 1980s. That model has recently undergone additional peer review. The reviewers identified four areas of concern related to the model and its application. This report describes revisions to the model in response to the reviewers' concerns. Model revision involved incorporation of explicit treatment of enhanced dispersion at low wind speeds in addition to explicit treatment of enhanced dispersion at high speeds resulting from building wakes. Model parameters are evaluated from turbulence data. Experimental diffusion data from seven reactor sites are used for model evaluation. Compared with models recommended in current NRC guidance to licensees, the revised model is less biased and shows more predictive skill. The revised model is also compared with two non-Gaussian models developed to estimate maximum concentrations in building wakes. The revised model concentration predictions are nearly the same as the predictions of the non-Gaussian models. On the basis of these comparisons of the revised model concentration predictions with experimental data and the predictions of other models, the revised model is found to be an appropriate model for estimating concentrations in the vicinity of buildings.
\end{abstract}





\section{SUMMARY}

U.S. Nuclear Regulatory Commission (NRC) guidance to licensees describes acceptable methods for estimating atmospheric concentrations of radionuclides and toxic chemicals in the vicinity of buildings for use in nuclear reactor control room habitability assessments. Earlier studies conducted for the NRC established that the methods for estimating concentrations in building wakes in the NRC guidance were extremely conservative and concentration predictions were not highly correlated with the results of dispersion experiments. The earlier studies resulted in development of a wake dispersion model that was less biased than the model suggested in NRC guidance and that predicted concentrations that were better correlated with measured concentrations.

At NRC staff request, the Pacific Northwest Laboratory convened an independent peer review panel to examine the new model. The panel met in May 1994. As a result of their review of the model, they arrived at four recommendations. These recommendations were:

1) The turbulence increment generated by buildings should be assumed to be proportional to the wind speed in accordance with accepted theory and physical reasoning.

2) The effects of meander during low wind speed conditions should be treated explicitly in the model, but the treatment should be separate from the treatment of building wakes.

3) An approach other than straight-line Gaussian models should be considered for determining concentrations when releases are from a building and receptors are on or near the building.

4) Appropriate subsets of the available data should be used to evaluate the model after the suggested changes have been made.

This report describes the changes made to the model in response to the panels' first and second recommendations and the compares the revised model with two non-Gaussian models developed to estimate maximum concentrations in building wakes. Two sets of data, collected at seven reactor sites, are used throughout the report to evaluate the revised model and facilitate comparisons among models.

The revised model for calculating concentrations in the vicinity of buildings is a Gaussian model that uses modified diffusion coefficients. The diffusion coefficients consist of three components. The first component is a standard diffusion coefficient used in other NRC models. The second component is a low speed correction to the standard diffusion coefficient. This correction, which accounts for enhanced dispersion resulting from meander, is largest at low wind speeds and decreases as the wind 
speed increases. The third component of the modified diffusion coefficient is a building-wake correction. This correction is a function of building area and wind speed. It is small at low wind speed and increases as the wind speed increases. Turbulence parameters in the revised model have been evaluated using experimental data. In addition, one parameter in each of the diffusion coefficients models has been adjusted to minimize the difference between predicted and measured concentrations. The optimum values for these parameters are within the expected ranges, which indicates a general robustness of the model.

This report includes comparisons of concentrations predicted by the revised model with the predictions of models included in the current NRC guidance and with.predictions of two non-Gaussian models developed to estimate maximum concentrations in building wakes. The predictions of the revised model are better than those of the models in current regulatory guidance. Specifically, the concentrations predicted by revised model are less biased than those predicted by the current model for the low wind speed conditions that are most significant in control room habitability assessments. Further, the revised model concentration predictions are similar to the predictions of the maximum concentration models for receptor locations near the release point. This similarity demonstrates that the revised model may be used for control room habitability assessments, even though the concentration distributions may not be Gaussian in the vicinity of buildings. The revised model also is considered to be appropriate for dispersion calculations in the near field for use in evaluating the consequences of design basis accidents. 


\section{ACKNOWLEDGMENTS}

In the mid-1980s, the staff of the U.S. Nuclear Regulatory Commission (NRC) felt that its guidance to licensees related to calculating atmospheric concentrations of radionuclides and toxic chemicals in the vicinity of buildings was overly conservative. Consequently, the Pacific Northwest Laboratory undertook evaluation of the NRC guidance and development of new building-wake dispersion models. This report describes the model that has evolved in this process. As the model development comes to completion, we would like to express our thanks to current and former NRC staff who have supported this work. These individuals include the Technical Monitor for the current effort, Jay Y. Lee; Technical Monitors for earlier work, James E. Fairobent and Charles Ferrell; and interested individuals, Irv Spickler, Barry Zalcman, and Jack Hayes. In addition, we would like to thank the individuals, especially the peer reviewers, who have taken time to review our work, offer comments, and suggest revisions. 



\section{CONTENTS}

ABSTRACT $\ldots \ldots \ldots \ldots \ldots \ldots \ldots \ldots \ldots \ldots \ldots \ldots \ldots \ldots \ldots \ldots \ldots \ldots$ iii

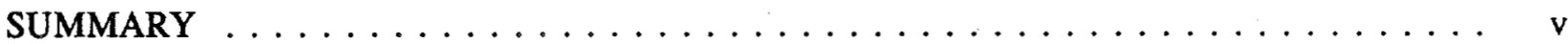

ACKNOWLEDGMENTS $\ldots \ldots \ldots \ldots \ldots \ldots \ldots \ldots \ldots \ldots \ldots \ldots$ vii

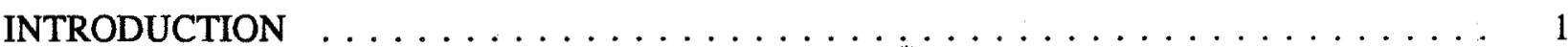

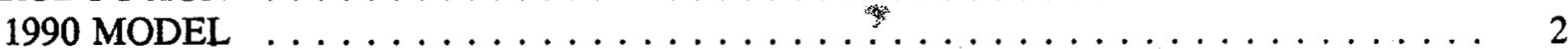

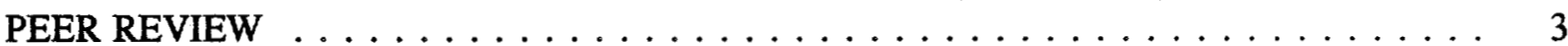

EXPERIMENTAL DATA ....................... 4

REVISED MODEL $\ldots \ldots \ldots \ldots \ldots \ldots \ldots \ldots \ldots \ldots \ldots \ldots$

GENERAL FORM FOR DIFFUSION INCREMENTS $\ldots \ldots \ldots \ldots \ldots \ldots \ldots$

LOW-SPEED INCREMENT $\ldots \ldots \ldots \ldots \ldots \ldots \ldots \ldots \ldots \ldots \ldots$

HIGH-SPEED INCREMENT $\ldots \ldots \ldots \ldots \ldots \ldots \ldots \ldots \ldots \ldots \ldots \ldots \ldots$

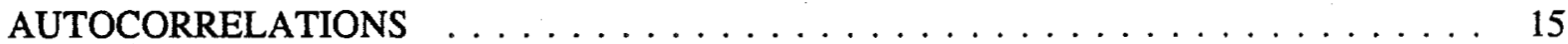

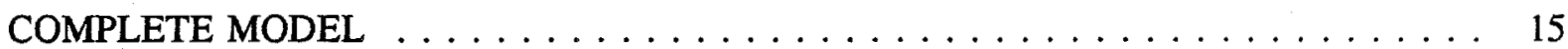

MODEL EVALUATION $\ldots \ldots \ldots \ldots \ldots \ldots \ldots \ldots \ldots \ldots \ldots$

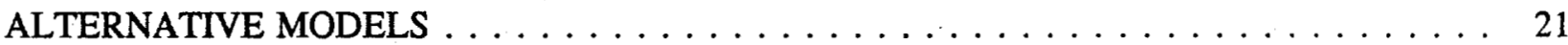

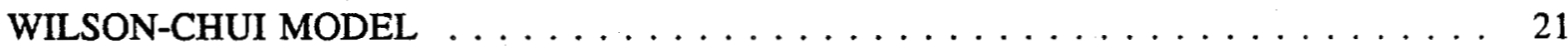

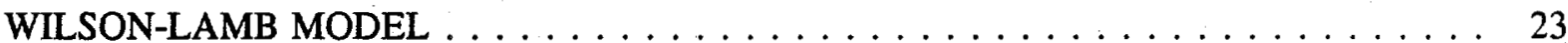

COMPARISON OF THE REVISED MODEL WITH THE ALTERNATIVES $\ldots \ldots \ldots$

NEAR-FIELD CONCENTRATION ESTIMATES . . . . . . . . . . . . . . . . 26

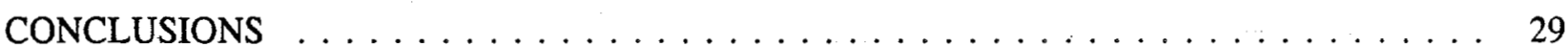

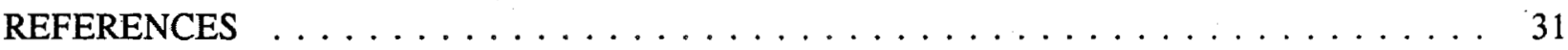

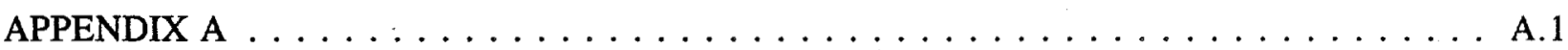

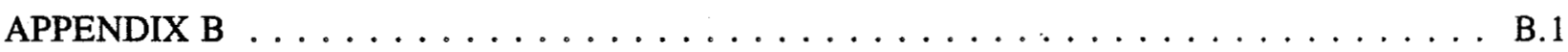




\section{FIGURES}

1 Variation of Low Speed Diffusion Coefficient Increments as Functions of Distance . . . . . 10

2 Variation of Low Speed Diffusion Coefficient Increments as Functions of Wind Speed . . . . 11

3 Increase in Lateral Turbulence as Function of Wind Speed $\ldots \ldots \ldots \ldots \ldots$

4 Increase in Vertical Turbulence as Function of Wind Speed . . . . . . . . . . . . 13

5. Variation of High Speed Diffusion Cổefficient Increments as Functions of Distance . . . . . 14

6 Variation of High Speed Diffusion Coefficient Increments as Functions of Wind Speed . . . . 14

7 Comparison of Revised Model Concentration Predictions with Observed Values . . . . . . 16

8 Bias in Murphy-Campe Model Concentration Predictions $\ldots \ldots \ldots \ldots \ldots$

9 Bias in Regulatory Guide 1.145 Model Concentration Predictions . . . . . . . . . . 18

10 Bias in Revised Model Concentration Predictions $\ldots \ldots \ldots \ldots \ldots$

11 Cumulative Frequency Distributions of Predicted to Observed Concentration Ratios for the Murphy-Campe, Regulatory Guide 1.145, and Revised Models . . . . . . . . . . . 19

12 Comparison of Wilson-Chui Model Concentration Predictions with Observed Values . . . . 22

13 Comparison of Wilson-Lamb Model Concentration Predictions with Observed Values . . . . 24

14 Comparison of Revised Model Concentration Estimates with Observed Values in the

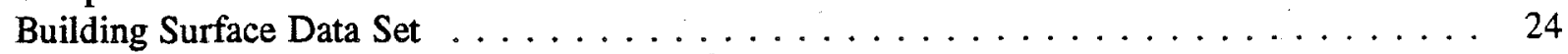

15 Comparison of Cumulative Frequency Distributions for the Ratios of Predicted to Observed Concentrations for the Wilson-Chui, Wilson-Lamb, and Revised Models . . . . . 25

16 Ratios of Predicted to Observed Concentrations for the Wilson-Chui Model $\ldots \ldots \ldots$

17 Ratios of Predicted to Observed Concentrations for the Wilson-Lamb Model . . . . . . . 27

18 Ratios of Predicted to Observed Concentrations for the Revised Model . . . . . . . . . 27

19 Cumulative Frequency Distributions of the Ratios Between Predicted and Observed Concentrations for the Wilson-Chui, Wilson-Lamb, and Revised Model for All Data : . . . 28 


\section{INTRODUCTION}

Control room habitability assessments and the evaluation of the consequences of design basis accidents involve estimating dispersion of effluents released from building vents and roof-level stacks. U. S. Nuclear Regulatory Commission (NRC) guidance to staff and licensees describes several acceptable methods for estimating dispersion in building wakes, for example, Regulatory Guide 1.145 (NRC 1982), and the Murphy-Campe procedure (Murphy and Campe 1974) referenced in Standard Review Plan 6.4 (NUREG-0800) (NRC 1987). These methods attempt to estimate the hourly-average concentration at the center of the plume downwind of the release point using equations based on the straight-line Gaussian model.

According to the Gaussian model, the concentration at center of a plume is

$$
\chi / Q=\frac{1}{\pi \sigma_{y} \sigma_{z} U}
$$

where $\quad \chi=$ the concentration $\left[\mathrm{Bq} / \mathrm{m}^{3},\left(\mathrm{Ci} / \mathrm{m}^{3}\right)\right]$

$\mathrm{Q}=$ the release rate $[\mathrm{Bq} / \mathrm{s},(\mathrm{Ci} / \mathrm{sec})]$

$\sigma_{y}, \sigma_{z}=$ the horizontal and vertical diffusion coefficients, respectively (m)
$U=$ wind speed $(\mathrm{m} / \mathrm{s})$.

Diffusion coefficients represent the effects of turbulence and are generally estimated on the basis of atmospheric stability and distance using empirical relationships derived from experimental data. Building-wake diffusion models have the same form but represent the effects of the wake by using modified diffusion coefficients. These models are typically written as

$$
\chi / Q=\frac{1}{\pi \Sigma_{y} \Sigma_{z} U}
$$

where $\Sigma_{\mathrm{y}}$ and $\Sigma_{\mathrm{z}}$ are diffusion coefficients, corrected for building wake effects.

Plume centerline concentrations predicted by the various NRC building wake models were compared with experimental data under NRC JCN B2970, "Atmospheric Diffusion for Control Room Habitability Assessments." The results of this work, published in NUREG/CR-5055 Atmospheric Diffusion for Control Room Habitability Assessments (Ramsdell 1988), show that the models do not predict the variations in concentrations that are related to changes in building area and atmospheric conditions very well. The results also show that the models significantly overpredict concentrations at low wind speeds. 


\subsection{MODEL}

An updated building-wake model (Ramsdell 1990) redefined $\Sigma_{y}$ and $\Sigma_{z}$. The new definition of $\Sigma_{y}$ is

$$
\Sigma_{y}=\left(\sigma_{y}^{2}+\Delta \sigma_{y b}^{2}\right)^{1 / 2}
$$

where $\sigma_{\mathrm{y}}$ describes the diffusion in the absence of a building wake, and $\Delta \sigma_{\mathrm{yb}}$ describes the increased diffusion in building wakes. This increased diffusion in wakes is estimated by

$$
\Delta \sigma_{y b}^{2}=\frac{2 r_{v} \Delta \sigma_{v b o}^{2} A}{u_{*}^{2}}\left[1-\left(1+\frac{\alpha x}{\sqrt{A}}\right) \exp \left(\frac{-\alpha x}{\sqrt{A}}\right)\right]
$$

where $r_{v}=$ a dimensionless constant with a value of about 1 that is equal to the average Lagrangian autocorrelation of the normal turbulence

$$
\begin{aligned}
\Delta \sigma_{\mathrm{vbo}}= & \begin{array}{l}
\text { the increase in the horizontal component of turbulence caused by the } \\
\text { building }(\mathrm{m} / \mathrm{s})
\end{array} \\
\mathrm{A}= & \text { the cross-sectional area of the building }\left(\mathrm{m}^{2}\right) \\
\mathrm{u}_{*}= & \text { a turbulence scaling velocity in the atmosphere that is related to wind speed, } \\
& \text { atmospheric stability, and surface roughness }(\mathrm{m} / \mathrm{s})
\end{aligned}
$$

The expression in brackets on the right side of Equation (4) controls the expansion of the plume as $x$ increases. It is equal to zero when $x$ is equal to 0 . For $x$ less than $0.2 \alpha / A^{1 / 2}$, the expression increases approximately as $x$, and when $x$ is greater than $5 \alpha / A^{1 / 2}$ the expression has its maximum value of 1.0. The coefficient $\alpha$ is a function of atmospheric stability and surface roughness. For near neutral atmospheric stability, the value of $\alpha$ is about 0.09 . Similar expressions with explicit dependence on atmospheric stability were derived for $\Sigma_{z}$.

Two notable assumptions related to $\Sigma_{y}$ and $\Sigma_{z}$ were made in development of the 1990 model. The first of these was that any of the standard sets of diffusion coefficient algorithms could be used to estimate diffusion in the absence of the wakes (normal diffusion). The second, and more critical, assumption was that $\Delta \sigma_{\mathrm{y}}$ and $\Delta \sigma_{\mathrm{z}}$ were independent of wind speed. With these assumptions and the 
parameterizations for normal diffusion coefficients found in most NRC computer codes, the 1990 model predicts centerline concentrations in wakes better than the models described in current regulatory guidance.

Commenting on the 1990 model, Briggs et al. (1992) point out that the increase in turbulence associated with building wakes should be a function of wind speed. They also point out that the improved predictions of the updated model at low wind speeds are more likely to be related to better treatment of meander than to treatment of building wakes.

\section{PEER REVIEW}

A panel was convened in May 1994 to conduct an additional peer review of the 1990 wake model. Appendix A lists the reviewers. The primary recommendations of this panel were:

1) The turbulence increment generated by buildings should be assumed to be proportional to the wind speed in accordance with accepted theory and physical reasoning.

2) The effects of meander during low wind speed conditions should be treated explicitly in the model, but the treatment should be separate from the treatment of building wakes.

3) An approach other than straight-line Gaussian models should be considered for determining concentrations when releases are from a building and receptors are on or near the building.

4) Appropriate subsets of the available data should be used to evaluate the model after the suggested changes have been made.

This report describes the disposition of the recommendations of the peer review panel. In addition to this introduction, the report consists of two sections that directly address the peer review panel recommendations. These sections describe the model revisions, compare the concentrations predicted by the revised model with measured concentrations, and compare the concentrations predicted by the revised model with concentrations predicted by alternative models.

The first section discusses revisions to the model to separate the effects of low and high wind speed phenomena on diffusion, and the second section discusses alternative models for situations in which receptors are on or adjacent to the structure from which the release occurs. Both sections discuss model performance and compare model predictions with observed data. The discussion and model comparisons in the second section are directly applicable to diffusion estimates related to control room habitability assessments. A draft of this report was sent to the review panel members 
and several other individuals for comment." Reviewers, comments and responses to those comments are listed in Appendix B.

\section{EXPERIMENTAL DATA}

Two data sets are used in evaluating model performance. These sets consist of data collected in field experiments at seven different reactors. Three of the seven reactors- the Materials Test Reactor--Engineering Test Reactor (Islitzer 1965), the Experimental Breeder Reactor-II (Dickson et al. 1969), and the Experimental Organically Cooled Reactor (EOCR) (Start et al. 1980) are at the Idaho National Engineering Laboratory. The remaining reactors are the Duane Arnold Energy Center in Iowa (Thuillier and Mancuso 1980, Thuillier 1982), Diablo Canyon Power Plant (Thuillier 1992) and Rancho Seco Nuclear Power Station (Start et al. 1978) in California, and the Three Mile Island Nuclear Power Station (GPUSC 1972) in Pennsylvania.

The first data set, referred to as the ground-level data set, consists of concentration measurements made at regular intervals on sampling arcs from 50 to 1200 meters from ground-level release points. In some cases the actual release point was offset from the center of the sampling arc. As a result, the range of distances of the data points in the ground-level data set is 8 to 1200 meters.

The maximum concentration on each arc was selected as the best approximation of concentration at the center of the plume as it crossed the arc. There is no assurance that this value is the maximum concentration in the plume. However, in most cases, the maximum concentration on the arc should be within a factor of two the maximum concentration in the plume.

The ground-level data set is described in earlier publications (Ramsdell 1988, 1990). The data have been used as reported except that stability classes have been modified in a few cases where the stability class determined by the NRC $\Delta \mathrm{T}$ method (NRC 1972) was inconsistent with other reported data, for example wind speed or season and time of day. These modifications typically involved changing extremely unstable or extremely stable stability classes to more nearly neutral stability classes. Neutral stability was assumed for all experiments in which the wind speed exceeded $6 \mathrm{~m} / \mathrm{s}$.

Meteorological conditions during the releases ranged from extremely stable (stability class $G$ ) to extremely unstable (stability class A), and wind speeds ranged from less than $1 \mathrm{~m} / \mathrm{s}$ to greater than 10 $\mathrm{m} / \mathrm{s}$. Of the 379 data points in the set, 253 represent measurements made with wind speeds less than $4 \mathrm{~m} / \mathrm{s}, 208$ data points represent measurements made during stable atmospheric conditions, and 138 
data points represent measurements in low wind speed, stable atmospheric conditions. This emphasis on low wind speed, stable conditions is appropriate because concentrations predicted for these conditions typically provide the limiting case in evaluation of consequences of accidental releases in control room habitability assessments.

The second data set, referred to as the building surface data set, consists of 265 concentration measurements made at locations on and adjacent to buildings at Rancho Seco, the Duane Arnold Energy Center, and the EOCR. Data from both ground-level and elevated release points are included in the data set. Meteorological conditions represented cover the full range of stabilities and wind speeds from less than $1 \mathrm{~m} / \mathrm{s}$ to almost $10 \mathrm{~m} / \mathrm{s}$. More than half of the data points represent measurements in low wind speed, stable conditions. All of the measurements were made less than 100 meters from the release point.

The samplers were not arranged in patterns that would ensure a reasonable likelihood that the concentration at the center of the plume was captured at each distance. As a result, these data are not appropriate for use in developing a model to predict centerline concentrations. However, centerline concentrations predicted by a model should tend to form an upper bound for the measured concentrations. Therefore, these data can be used to evaluate model performance. 



\section{REVISED MODEL}

The first two recommendations of the peer review group have been addressed by revising the 1990 building wake model. The revisions add a diffusion increment directly related to wind speed and modify the existing increment to be more directly related to low wind speed conditions.

Revision of the model starts by redefinition of diffusion coefficients, $\Sigma_{y}$ and $\Sigma_{z}$. The new definition of $\Sigma_{\mathrm{y}}$ is

$$
\Sigma_{y}=\left(\sigma_{y 0}^{2}+\Delta \sigma_{y 1}^{2}+\Delta \sigma_{y 2}^{2}\right)^{1 / 2}
$$

where $\sigma_{\mathrm{yo}}$ represents diffusion from a point source under normal conditions, $\Delta \sigma_{\mathrm{y} 1}$ represents an increment to diffusion associated with low wind speed phenomena, and $\Delta \sigma_{\mathrm{y} 2}$ represents an increment to diffusion associated with high wind speeds. A similar expression defines $\Sigma_{z}$.

To maintain continuity with existing regulatory guidance, the relationships used to define the diffusion coefficients in the NRC PAVAN (Bander 1982) and XOQDOQ (Sagendorf et al. 1982) codes are assumed to be applicable for $\sigma_{\mathrm{yo}}$ and $\sigma_{\mathrm{zo}}$. The relationships were developed initially by Martin and Tikvart (1968) and Tadmor and Gur (1969) as approximations to the Pasquill-Gifford diffusion coefficient curves. Gifford (1976) describes the Pasquill-Gifford curves and other diffusion coefficient parameterizations. The relationships of Martin and Tikvart and Tadmor and Gur have been extended to include stability class $G$ following the guidance in the February 1983 reissue of Revision 1 of NRC Regulatory Guide 1.145.

\section{GENERAL FORM FOR DIFFUSION INCREMENTS}

Derivation of expressions for $\Delta \sigma_{\mathrm{y} 1}, \Delta \sigma_{\mathrm{y} 2}$, and the corresponding increments to vertical diffusion generally follows the derivation of the diffusion increments in the original wake model. The derivation starts by assuming that some phenomenon or combination of phenomena causes an increase in turbulence above the turbulence implicitly assumed in the normal diffusion coefficients. At low wind speeds, meander and possibly uneven heating of building surfaces may be responsible for increased diffusion. At high wind speeds, the mechanical turbulence associated with wakes is responsible for increased diffusion. In addition, the effect of each turbulence increment on diffusion is assumed to decrease exponentially as a function of time relative to an appropriate time scale.

With these assumptions, a horizontal diffusion coefficient increment is defined by 


$$
\Delta \sigma_{y}^{2}=2 \iint \Delta \sigma_{v}^{2} \exp \left(-t / T_{\Delta v}\right) R_{v}(\tau) d \tau d t
$$

where $\Delta \sigma_{\mathrm{v}}$ is the increase in the lateral component of the turbulence, $\mathrm{t}$ is the time since release, $\mathrm{T}_{\Delta \mathrm{v}}$ is the time scale of the turbulence increment, and $R_{V}(\tau)$ is the Lagrangian autocorrelation function for the background turbulence. If $R_{v}(\tau)$ is assumed to have a constant value, $r_{v}$, near the release point, the double integral in Equation (6) has the solution

$$
\Delta \sigma_{y}^{2}=2 r_{v} \Delta \sigma_{v}^{2} T_{\Delta v}^{2}\left[1-\left(1+\frac{t}{T_{\Delta v}}\right) \exp \left(-\frac{t}{T_{\Delta v}}\right)\right]
$$

The integral in Equation (6) can also be solved if the Lagrangian autocorrelation for background turbulence is assumed to decay exponentially. The result, given in the paper describing the 1990 model (Ramsdell 1990), is more complicated than Equation (7). This additional complexity did not improve the predictive ability of the 1990 model. Therefore, the assumption of a constant value for $r_{v}$ is considered to be appropriate. Note that the value of $r_{v}$, and the value of $r_{w}$ in the equation for the vertical turbulence, will be determined using the ground-release data set.

It is important to note that the assumptions leading to Equations (6) and (7) involve two different time scales. There is a time scale associated with the turbulence increment that is denoted $T_{\Delta v}$. This time scale is shown explicitly in the model equations. The second time scale is associated with the background turbulence. This time scale is not shown explicitly in the equations, but it is implicit in the Lagrangian autocorrelation function.

The first part of the expression on the right side of Equation (7), $2 r_{v} \Delta \sigma_{v}{ }^{2} T_{\Delta v}{ }^{2}$, determines the maximum increment to the diffusion coefficient. The second part of the expression, which is in brackets, determines the fraction of the maximum increment that is applied as the time (or distance) increases. This term is zero at the release point and asymptotically approaches one as the distance increases. Two consequences of this behavior are 1) that the model does not predict instantaneous diffusion at the release point, and 2) that $\Sigma_{y}$ approaches $\sigma_{\text {yo }}$ at large distances. It is not necessary to apply arbitrary limits to the model to avoid unrealistic asymptotic behavior either near the source or at large distances. 


\section{LOW-SPEED INCREMENT}

The relationship in Equation (7) is general and may be used to define $\Delta \sigma_{\mathrm{y} 1}{ }^{2}, \Delta \sigma_{\mathrm{y} 2}{ }^{2}, \Delta \sigma_{\mathrm{z} 1}{ }^{2}$; and $\Delta \sigma_{\mathrm{z} 2}{ }^{2}$ provided the appropriate turbulence increments and time scales are used in each case.

Therefore, the low-speed diffusion increments are

$$
\Delta \sigma_{\mathrm{y} 1}^{2}=2 \mathrm{r}_{\mathrm{v}} \Delta \sigma_{\mathrm{v} 1}^{2} \mathrm{~T}_{\Delta \mathrm{v} 1}^{2}\left[1-\left(1+\frac{\mathrm{t}}{\mathrm{T}_{\Delta \mathrm{v} 1}}\right) \exp \left(-\frac{\mathrm{t}}{\mathrm{T}_{\Delta \mathrm{v} 1}}\right)\right]
$$

and

$$
\Delta \sigma_{z}^{2}=2 r_{w} \Delta \sigma_{w 1}^{2} T_{\Delta w 1}^{2}\left[1-\left(1+\frac{t}{T_{\Delta w 1}}\right) \exp \left(-\frac{t}{T_{\Delta w 1}}\right)\right]
$$

where the subscript 1 denotes low wind speed. These increments are corrections to the normal diffusion coefficient parameterizations and are not related to building wakes.

The diffusion data available listed above, except Diablo Canyon, include measurements of the standard deviation of the wind direction, $\sigma_{\theta}$. These wind measurements, along with wind data reported by Sagendorf and Dickson (1974) and Ogawa and Oikawa (1982) were used to examine the low-speed lateral turbulence increment. For each experiment the measured $\sigma_{\theta}$ was converted to $\sigma_{\mathrm{v} l}$. A corresponding value of $\sigma_{\mathrm{v}}{ }^{*}$ implicit in the NRC diffusion parameterization was computed using $\sigma_{\mathrm{y}}$ at $100 \mathrm{~m}$ for the stability class of the experiment. The lateral turbulence increment, $\Delta \sigma_{\mathrm{v} 1}$, for each experiment was then computed as

$$
\Delta \sigma_{\mathrm{v} 1}=\left(\sigma_{\mathrm{v}}^{2}-\sigma_{\mathrm{v}}{ }^{* 2}\right)^{1 / 2}
$$

In a few cases the difference on the right side of Equation (10) was negative. These differences were set to zero. With this adjustment, the average $\Delta \sigma_{\mathrm{v} 1}$ was $0.835 \mathrm{~m} / \mathrm{s}$. Using a similar approach and data presented by Islitzer (1965), Dickson et al (1969), and Ogawa and Oikawa (1982), an average of $0.239 \mathrm{~m} / \mathrm{s}$ was calculated for $\Delta \sigma_{\mathrm{w} 1}$. Neither $\Delta \sigma_{\mathrm{v} 1}$ nor $\Delta \sigma_{\mathrm{w} 1}$ varies significantly as a function of atmospheric stability or wind speed.

Assuming that meander is the primary factor responsible for the low-speed diffusion increment, a time scale of $1000 \mathrm{~s}$ has been selected for the horizontal turbulence increment. This time scale is somewhat larger than the time scale of $300 \mathrm{~s}$ suggested by Draxler (1976) for surface sources. However, the model is not sensitive to this time scale. Time scales of $300 \mathrm{~s}$ and $500 \mathrm{~s}$ give results 
that, while not quite as good as those obtained with a time scale of $1000 \mathrm{~s}$, are probably not significantly different from those obtained with a 1000 -s time scale.

The time scale selected for the vertical diffusion increment is $100 \mathrm{~s}$. This time scale is slightly longer than the inverse of the Brunt-Vaisala frequency for the temperature lapse rate separating stability classes D and E as defined in Regulatory Guide 1.23 (NRC 1972). This is also the time scale estimated by Draxler for diffusion from surface releases.

Figures 1 and 2 show the variation of the low-speed diffusion increments with distance and wind speed, respectively. Autocorrelation values determined in a later section have been a assumed for these calculations. Figure 1 shows that the low speed diffusion increments reach limiting values as the distance from the release point increases. Figure 2 shows that these increments decrease with increasing wind speed.

Changing values for the correlation coefficients or turbulence increments moves the curves in these figures vertically. In contrast, changing the time scale does not change the position of the curves. It changes the distance at which maximum diffusion increments occur (Figure 1) and the maximum diffusion increment at low wind speeds (Figure 2). The lateral diffusion increment shown

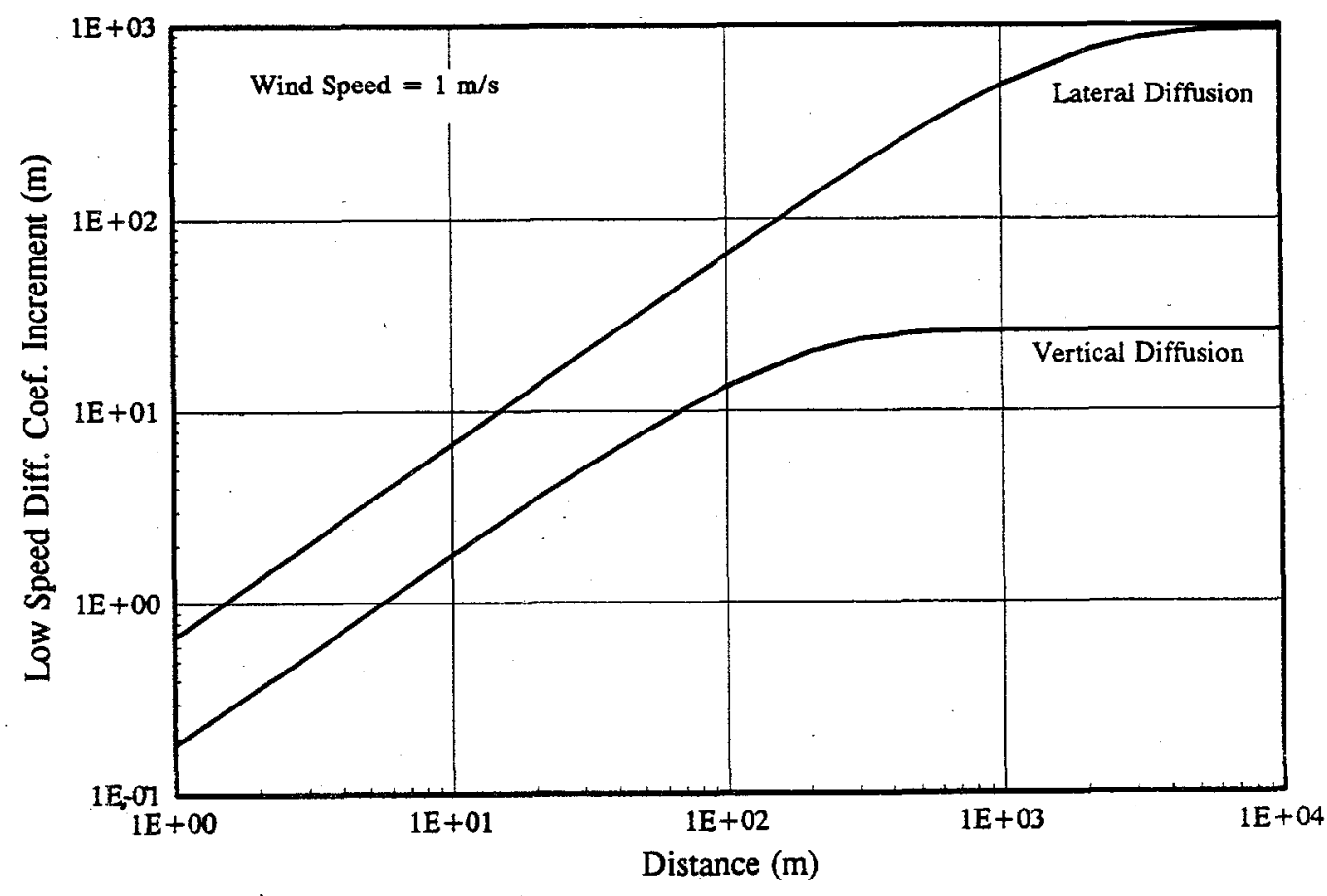

Figure 1. Variation of Low Speed Diffusion Coefficient Increments as Functions of Distance 


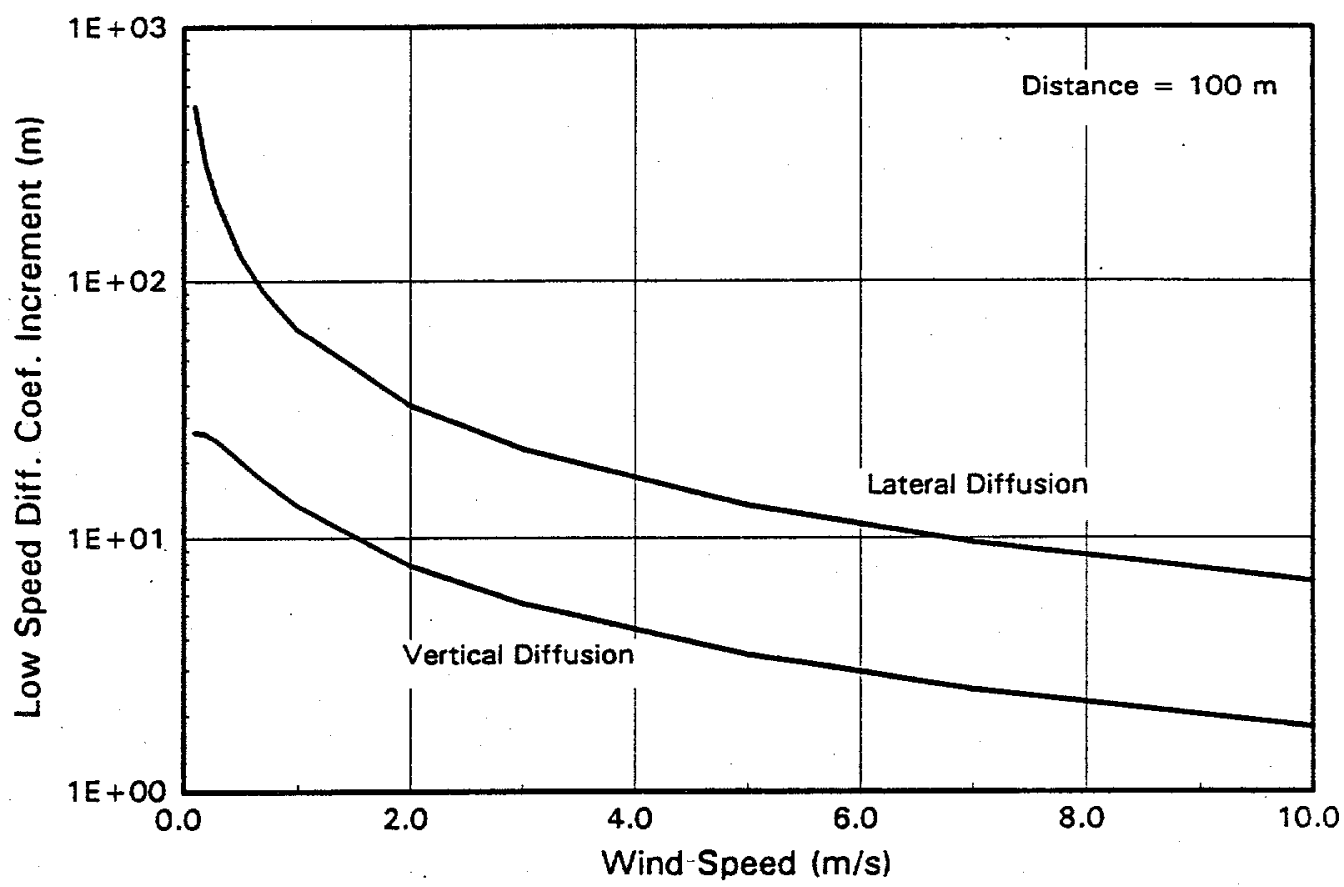

Figure 2. Variation of Low Speed Diffusion Coefficient Increments as Functions of Wind Speed

in Figure 2 is bounded as the wind speed approaches zero. The upper bound is clearly too large; however, it is not reasonable to allow the wind speed to approach zero in standard plume models. A model derived by Frenkiel (1953) is more appropriate for extremely low wind speeds. For a discussion of this model see Kao (1984).

\section{HIGH-SPEED INCREMENT}

Turbulence data published by Islitzer (1965), Dickson et al. (1969), and Ogawa and Oikawa (1982) were used to develop parameterizations for turbulence increments during high wind speeds. Using these data, high-speed lateral turbulence increments, $\Delta \sigma_{\mathrm{v} 2}$, were computed as

$$
\Delta \sigma_{v 2}=\left(\sigma_{v d}^{2}-\sigma_{v v}^{2}\right)^{1 / 2}
$$

where the $u$ and $d$ subscripts represent upwind and downwind measurements, respectively. In several instances, the subtraction resulted in negative differences. These differences were considered to be unreal and were set to zero. The same procedure was used to calculate $\Delta \sigma_{\mathrm{w} 2}$ for each experiment. 
The resulting turbulence increments are plotted against the square of the upwind wind speed in Figures 3 and 4. As suggested by the peer review panel, these increments are functions of wind speed. The constants of proportionality between the turbulence increments and the square of the upwind wind speed are 0.02 and 0.01 for $\Delta \sigma_{\mathrm{v} 2}$ and $\Delta \sigma_{\mathrm{w} 2}$, respectively. These coefficients are dimensional with units of seconds per meter. The correlation coefficient for the relationship shown in

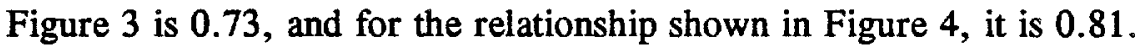

The characteristics of turbulence near structures, including variances and scales change as the distance from the structure increases. Consequently, no single time scale is appropriate for use in wakes. Tennekes and Lumley (1972) describe the difficulty in estimating scales in decaying wake turbulence. Nevertheless, an average time scale will be assumed for decay of both the lateral and vertical turbulence increments in the wake. This time scale is estimated as .

$$
T_{\Delta 2}=\frac{\alpha \sqrt{A}}{U}
$$

where $\alpha$ is a proportionality constant, $\mathrm{A}$ is the cross-sectional area of the structure generating the

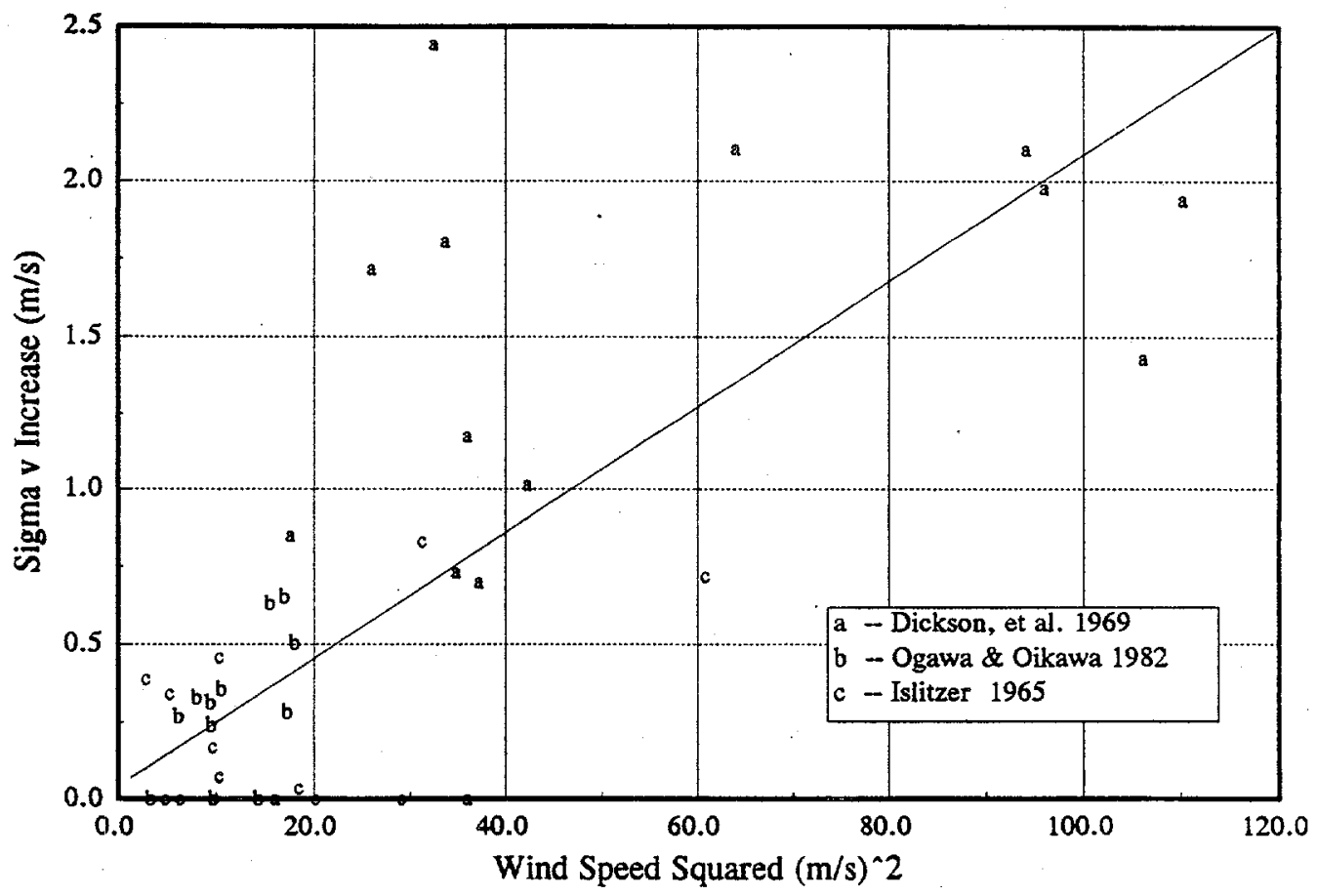

Figure 3. Increase in Lateral Turbulence as Function of Wind Speed 


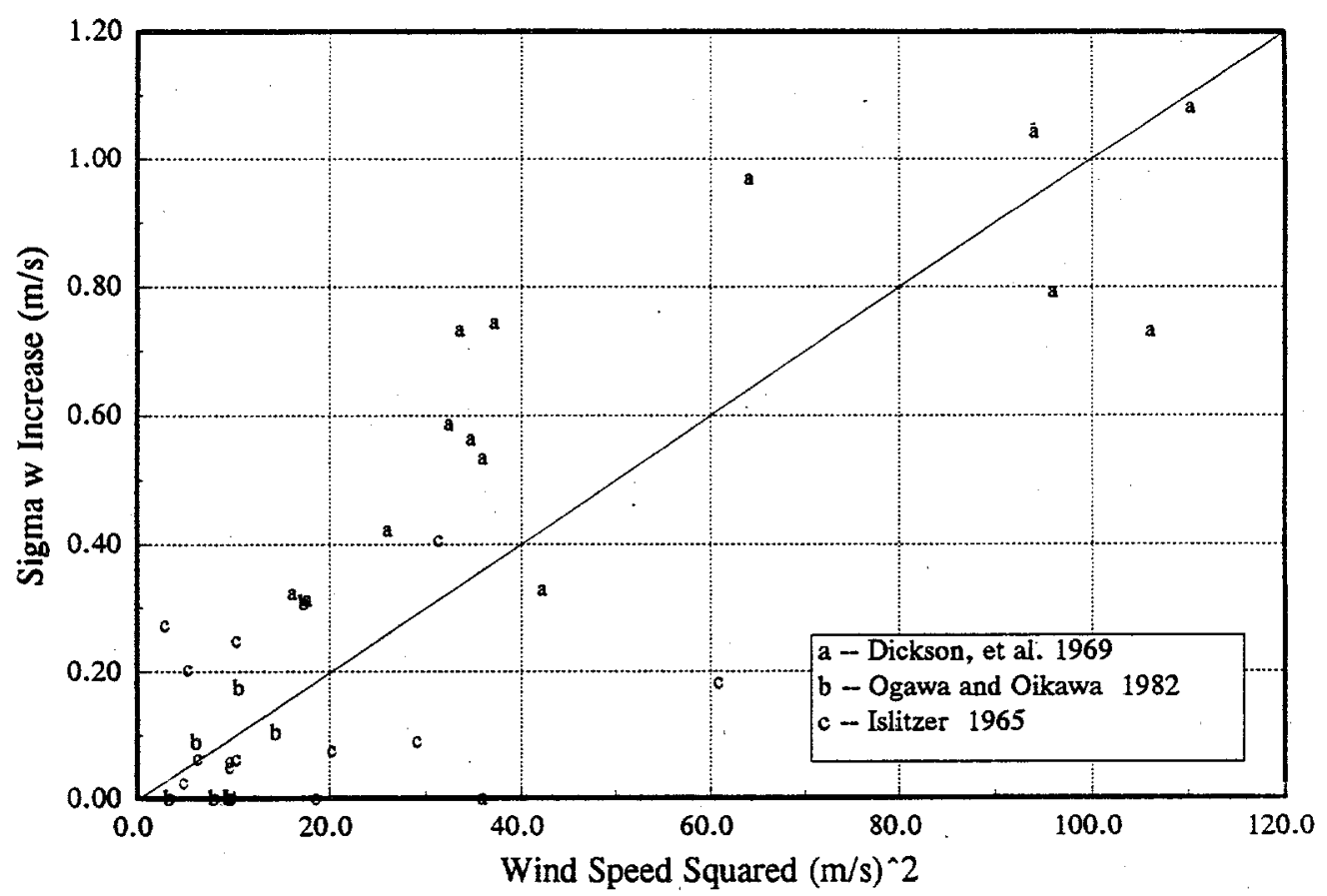

Figure 4. Increase in Vertical Turbulence as Function of Wind Speed

increased turbulence, and $U$ is the release height wind speed upwind of the building. A proportionality constant of about 10 gives good results. The model results are not particularly sensitive to the exact value chosen for this time scale.

Figures 5 and 6 show the variation in the high speed diffusion coefficient increments downwind of a building with a cross-sectional area of $1600 \mathrm{~m}^{2}$. Again, the autocorrelation coefficients estimated in the next section have been assumed. 


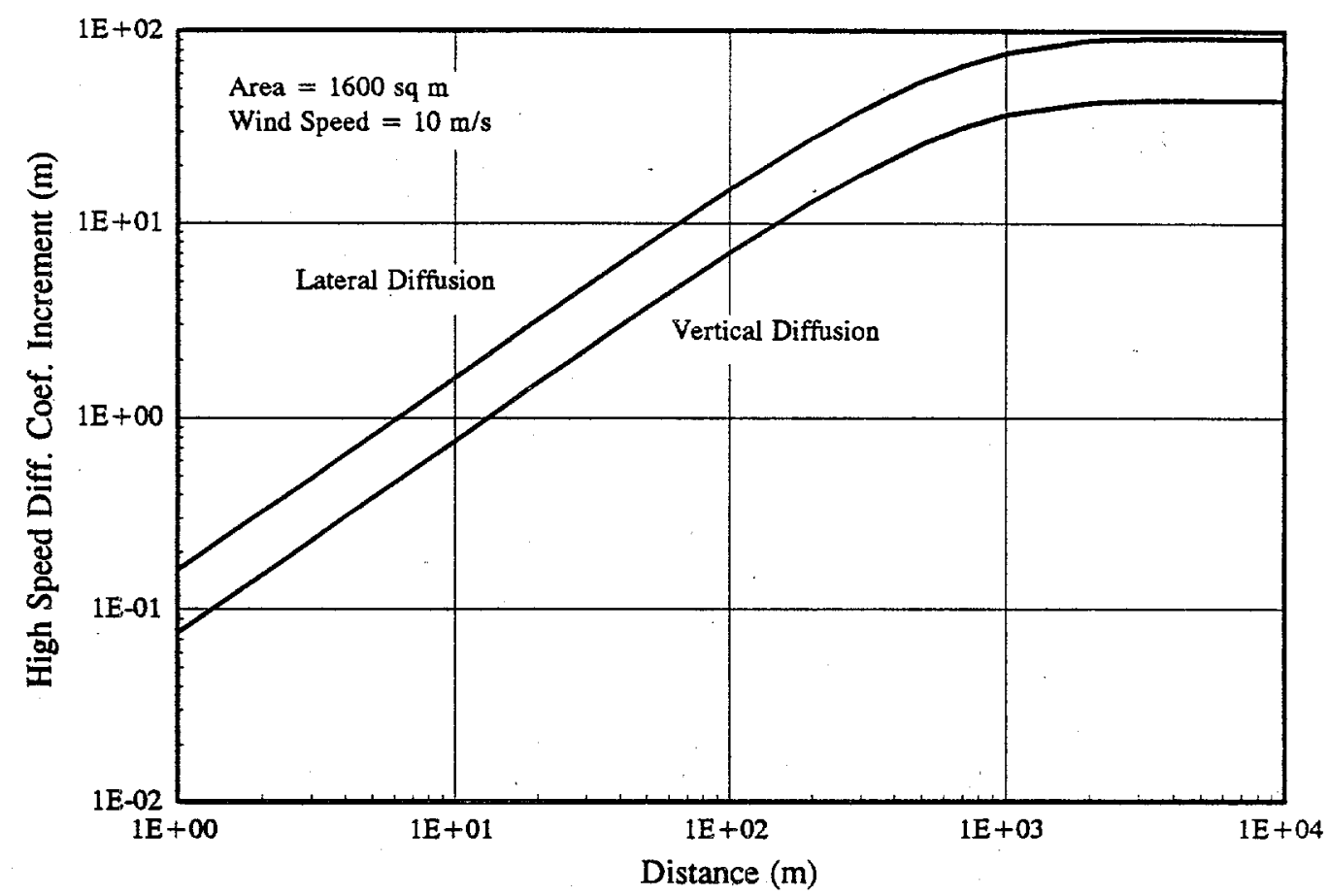

Figure 5. Variation of High Speed Diffusion Coefficient Increments as Functions of Distance

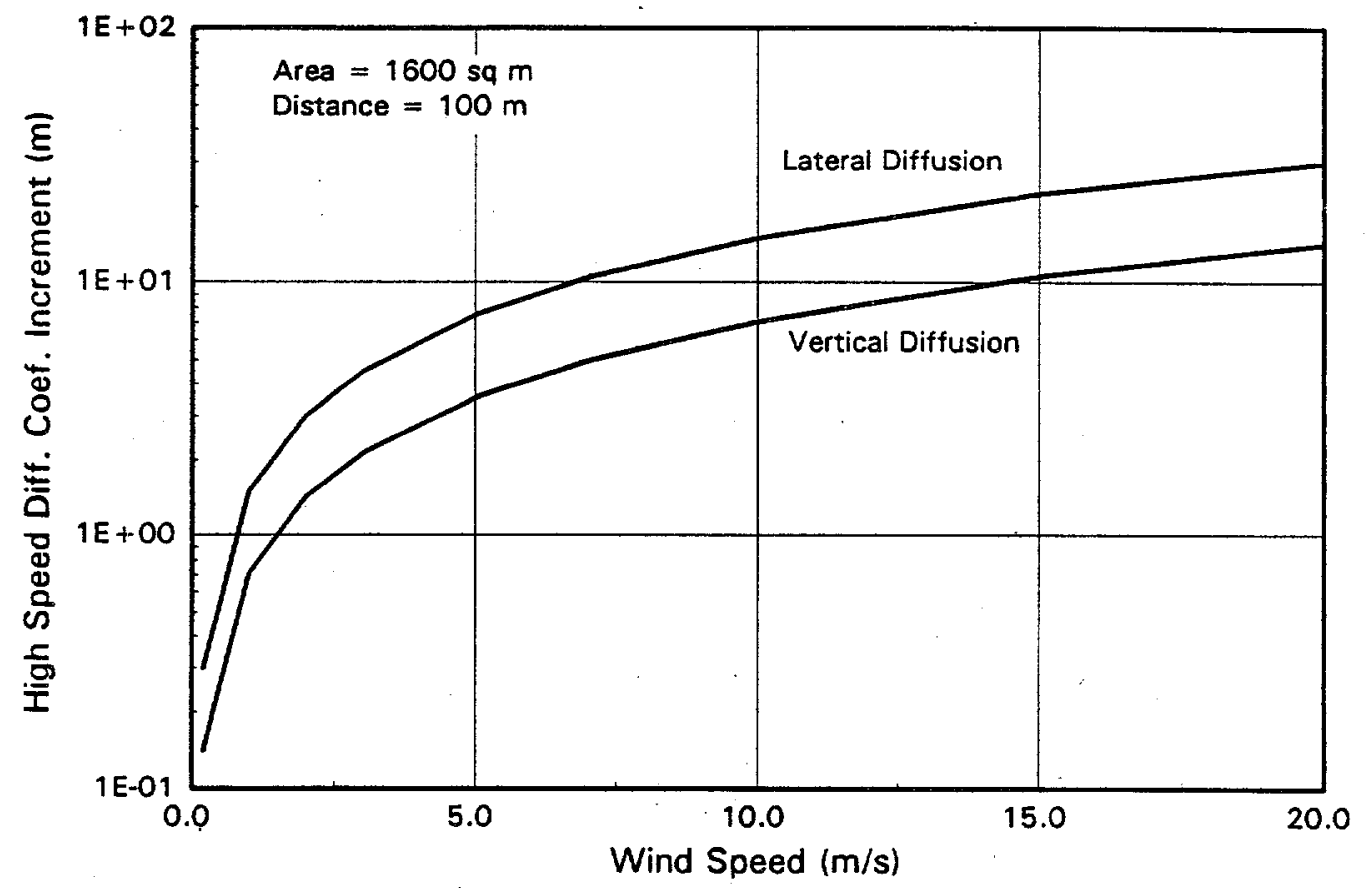

Figure 6. Variation of High Speed Diffusion Coefficient Increments as Functions of Wind Speed 


\section{AUTOCORRELATIONS}

The model definition is complete except for specification of average values for the Lagrangian autocorrelations, $r_{v}$ and $r_{w}$. The diffusion data in the ground-level data set were used to determine values for these parameters. The values were determined by minimizing the function

$$
P=\Sigma W_{i}\left[\log \left(\frac{X_{i}}{Q}\right)_{\text {pred }}-\log \left(\frac{X_{i}}{Q}\right)_{\text {mess }}\right]^{2}
$$

where $\left(\chi_{\mathbf{i}} / Q\right)_{\text {pred }}$ is the normalized concentration predicted by the model, $\left(\chi_{i} / Q\right)_{\text {meas }}$ is the normalized concentration measured in the ground-level data set for the same conditions, and $\mathrm{W}_{\mathrm{i}}$ is a weighting function. The weighting function was set to 1.0 when the model overpredicted the measured concentration and to 2.0 when the model underpredicted it. These weights were selected to ensure that, on the average, the model is conservative.

The optimum values of $r_{v}$ and $r_{w}$ selected by the minimization procedure were 0.655 and 0.584 , respectively. When these values are incorporated in the model, the geometric mean ratio of predicted to observed concentrations is 1.42 with a median of 1.51 .

\section{COMPLETE MODEL}

Specification of the autocorrelations completes the model revision. The equations for $\Delta \sigma_{\mathrm{y} 1}{ }^{2}$, $\Delta \sigma_{\mathrm{z} 1}{ }^{2}, \Delta \sigma_{\mathrm{y} 2}{ }^{2}$, and $\Delta \sigma_{\mathrm{z} 2}{ }^{2}$ are:

$$
\begin{aligned}
\Delta \sigma_{y 1}{ }^{2} & =(2)(0.655)(0.835)^{2}(1000)^{2}\left[1-\left(1+\frac{t}{1000}\right) \exp \left(-\frac{t}{1000}\right)\right] \\
& =9.13 \times 10^{5}\left[1-\left(1+\frac{x}{1000 U}\right) \exp \left(-\frac{x}{1000 U}\right)\right] \\
\Delta \sigma_{z 1}^{2} & =(2)(0.584)(0.239)^{2}(100)^{2}\left[1-\left(1+\frac{t}{100}\right) \exp \left(-\frac{t}{100}\right)\right] \\
& =6.67 \times 10^{2}\left[1-\left(1+\frac{x}{100 U}\right) \exp \left(-\frac{x}{100 U}\right)\right]
\end{aligned}
$$




$$
\begin{aligned}
\Delta \sigma_{y^{2}}{ }^{2} & =(2)(0.655)\left(0.02 \mathrm{U}^{2}\right)^{2} \frac{100 \mathrm{~A}}{\mathrm{U}^{2}}\left[1-\left(1+\frac{\mathrm{Ut}}{10 \sqrt{\mathrm{A}}}\right) \exp \left(-\frac{\mathrm{Ut}}{10 \sqrt{\mathrm{A}}}\right)\right] \\
& =5.24 \times 10^{-2} \mathrm{U}^{2} \mathrm{~A}\left[1-\left(1+\frac{\mathrm{x}}{10 \sqrt{\mathrm{A}}}\right) \exp \left(\frac{-\mathrm{x}}{10 \sqrt{\mathrm{A}}}\right)\right]
\end{aligned}
$$

and

$$
\begin{aligned}
\Delta \sigma_{22}^{2} & =(2)(0.584)\left(0.01 \mathrm{U}^{2}\right)^{2} \frac{100 \mathrm{~A}}{\mathrm{U}^{2}}\left[1-\left(1+\frac{\mathrm{Ut}}{10 \sqrt{\mathrm{A}}}\right) \exp \left(\frac{-\mathrm{Ut}}{10 \sqrt{\mathrm{A}}}\right)\right] \\
& =1.17 \times 10^{-2} \mathrm{U}^{2} \mathrm{~A}\left[1-\left(1+\frac{\mathrm{x}}{10 \sqrt{\mathrm{A}}}\right) \exp \left(\frac{-\mathrm{x}}{10 \sqrt{\mathrm{A}}}\right)\right]
\end{aligned}
$$

respectively. Note that the numerical values for $\Delta \sigma_{\mathrm{v} 1}, \Delta \sigma_{\mathrm{w} 1}, \mathrm{r}_{\mathrm{v}}$, and $\mathrm{r}_{\mathrm{w}}$ are directly related to the diffusion coefficient parameterizations used in NRC dispersion models. The numerical values for these parameters are different for other diffusion coefficient parameterizations.

Figure 7 compares the predicted and measured concentrations for the revised model. Slightly more than $50 \%$ of the model predictions are within a factor of four of the measured values, and almost $85 \%$ are within a factor of ten of the measured values.

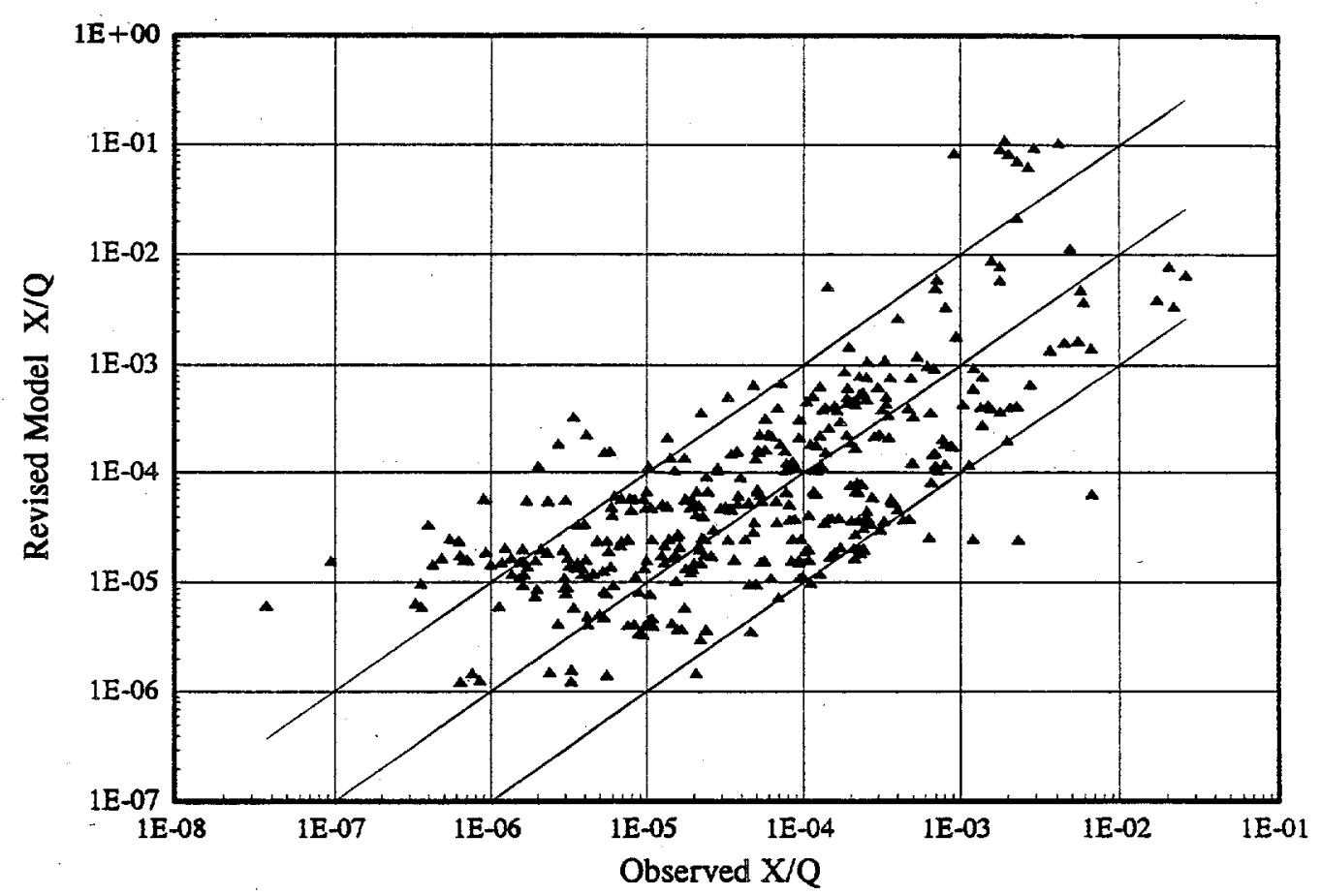

Figure 7. Comparison of Revised Model Concentration Predictions with Observed Values 


\section{MODEL EVALUATION}

Early evaluation of the current NRC wake models indicated that the models significantly overpredict concentrations during light winds (Ramsdell 1988). This tendency is shown in Figures 8 and 9. NRC guidance related to the use of these models states that the models should be used to determine $\chi / Q$ values that are exceeded no more than five percent of the time. Typically these highest values are associated with wind speeds of about $1 \mathrm{~m} / \mathrm{s}$. Figures 8 and 9 show that the current models almost always overpredict concentrations by an order of magnitude when the wind speed is 1 $\mathrm{m} / \mathrm{s}$ or less and that on the average they predict concentrations that are about two orders of magnitude too high. The diffusion experiments used for model evaluation may not have resulted in measurement of maximum concentrations in plumes. However, the bias that would be associated with the failure to measure maximum concentrations would be of the order of a factor of two. It would certainly not be one or two orders of magnitude. Therefore it is reasonable to conclude that the biases seen in these models are the result of the errors in the models rather than uncertainty in the data.

The revised model includes corrections to the diffusion coefficients specifically addressed to improving model performance at low wind speeds. Figure 10 shows the variation of ratio between

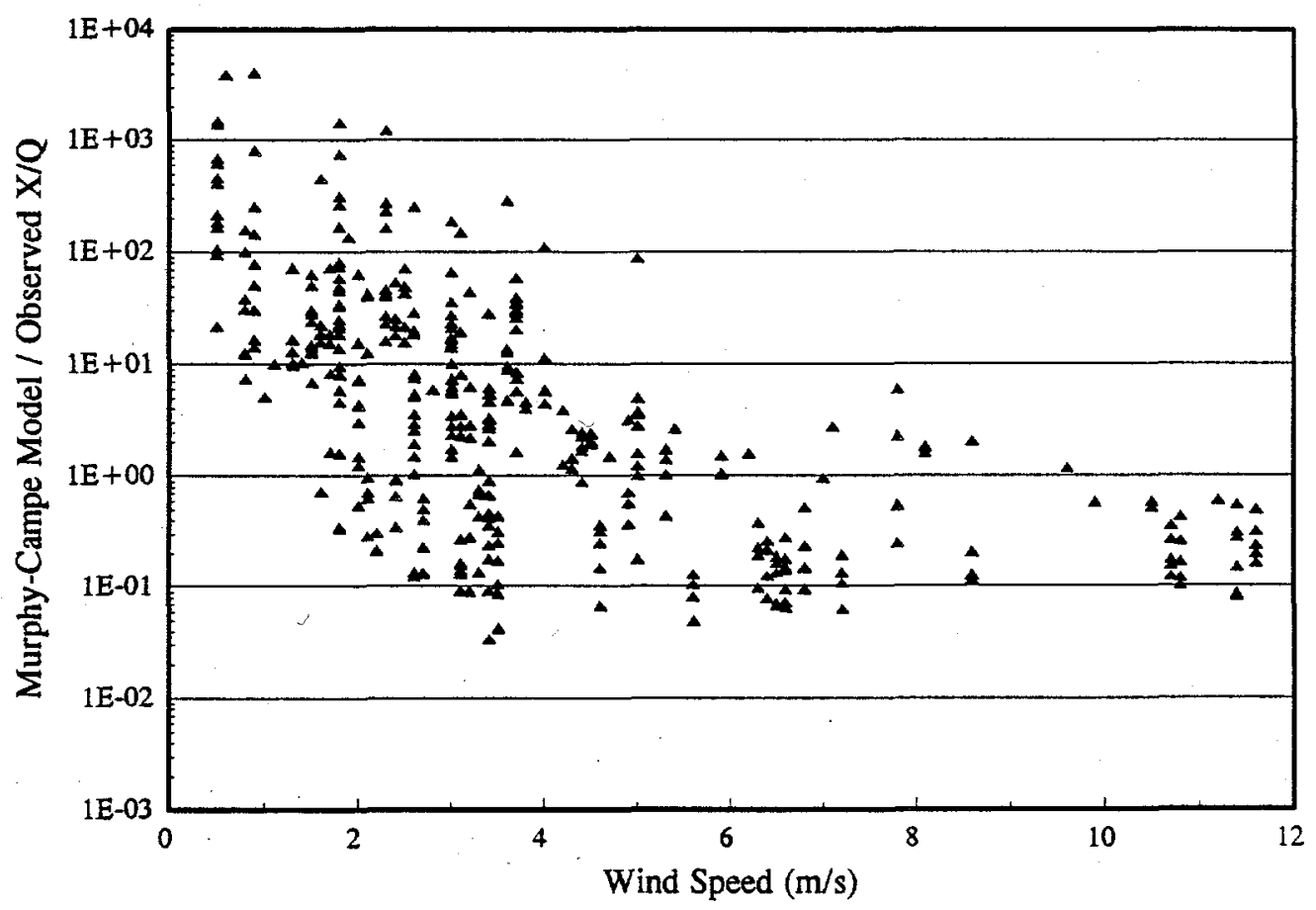

Figure 8. Bias in Murphy-Campe Model Concentration Predictions 


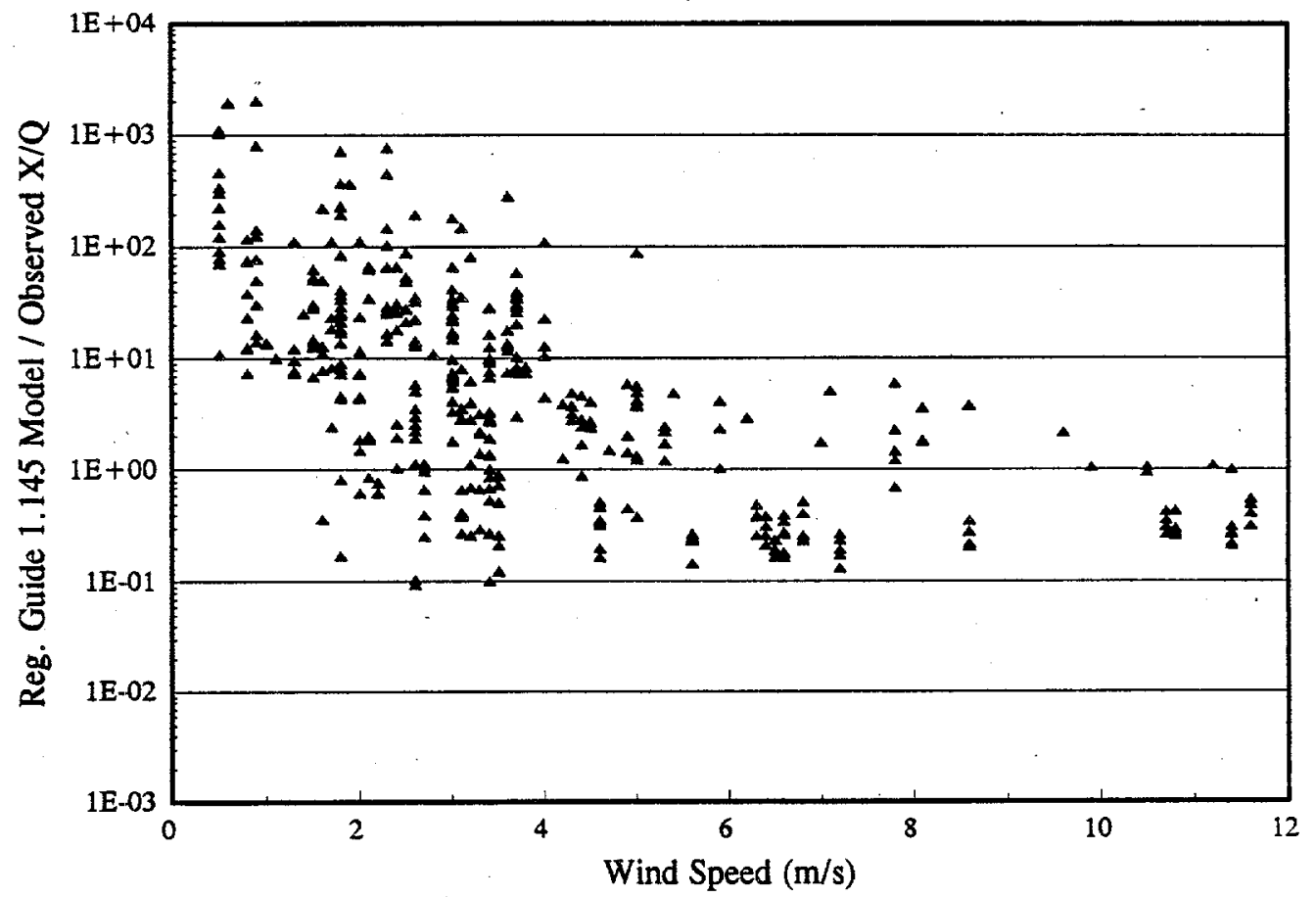

Figure 9. Bias in Regulatory Guide 1.145 Model Concentration Predictions

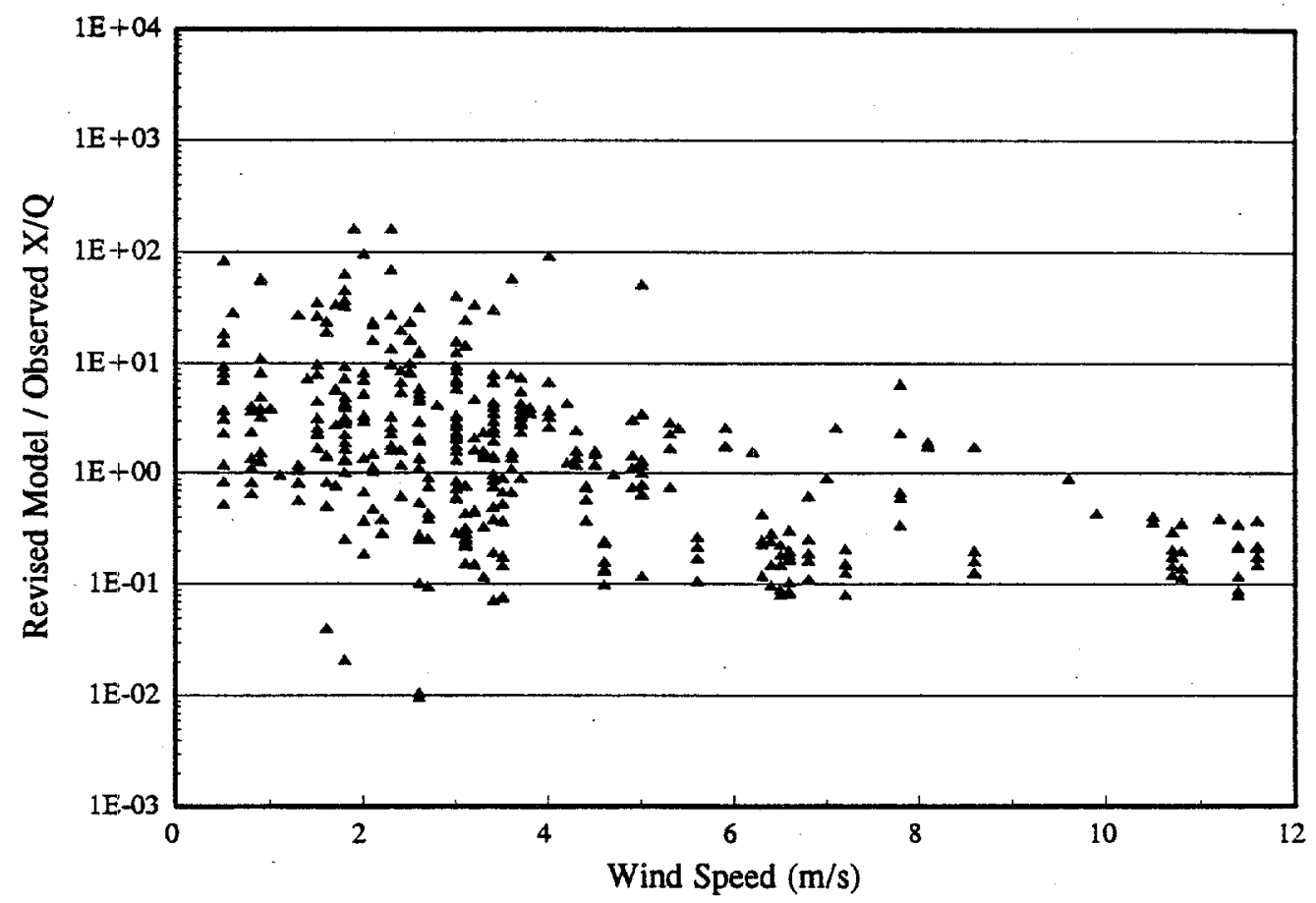

Figure 10. Bias in Revised Model Concentration Predictions 
predicted and observed concentrations for the revised model as a function of wind speed. Compared with the current NRC models, the revised model has less tendency to overpredict concentrations at low wind speed. However, it does appear that there is still a slight tendency toward overprediction for wind speeds less than $3 \mathrm{~m} / \mathrm{s}$. The improvement in model performance is further illustrated in the cumulative frequency distributions shown in Figure 11. The median ratios between concentrations predicted by current NRC models and the maximum observed concentrations are greater than three. In addition, concentrations predicted by the current models are within an order of magnitude of the observed concentrations only about $60 \%$ of the time. Figure 11 clearly shows that the improvement in model performance is gained by reducing model overpredictions without significantly increasing underpredictions. Summary statistics comparing the models are presented in Table 1.

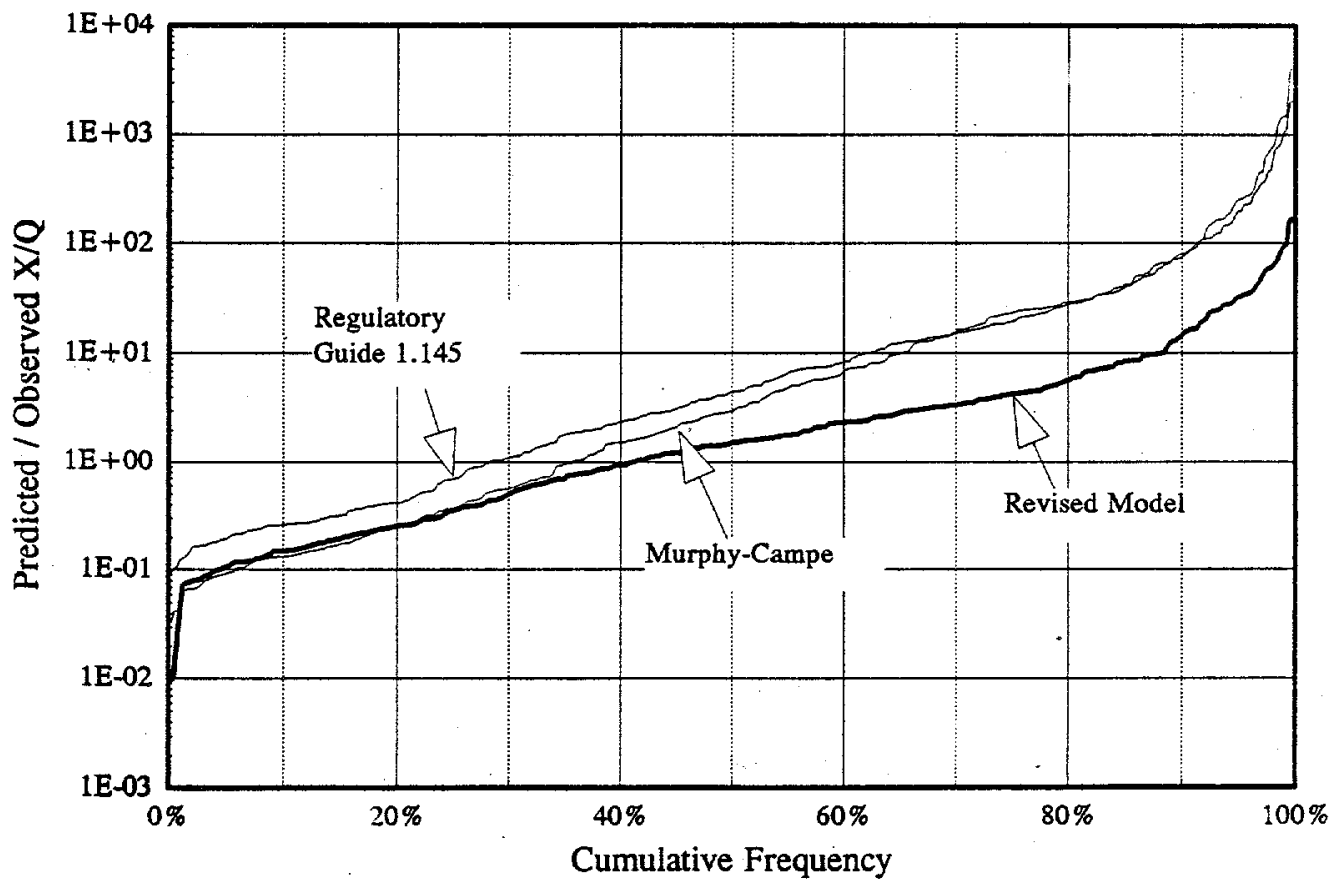

Figure 11. Cumulative Frequency Distributions of Predicted to Observed Concentration Ratios for the Murphy-Campe, Regulatory Guide 1.145, and Revised Models 
Table 1. Summary of Model Comparison Statistics

\begin{tabular}{||l|c|c|c||}
\hline \multicolumn{1}{|c|}{ Statistic } & Revised Model & $\begin{array}{l}\text { Murphy-Campe } \\
\text { Model }\end{array}$ & $\begin{array}{l}\text { Regulatory } \\
\text { Guide 1.145 } \\
\text { Model }\end{array}$ \\
\hline \hline $\begin{array}{l}\text { Median ratio of predicted to } \\
\text { measured concentrations }\end{array}$ & 1.510 & 2.935 & 4.451 \\
\hline Geometric mean ratio & 1.417 & 3.263 & 4.546 \\
\hline Geometric standard deviation of ratios & 0.757 & 1.075 & 0.944 \\
\hline Minimum ratio & 0.010 & 0.034 & 0.095 \\
\hline Maximum ratio & 166. & 4100. & 2050. \\
\hline $\begin{array}{l}\text { Predicted concentrations within a } \\
\text { factor of 2 of the measured values }\end{array}$ & $27.4 \%$ & $16.6 \%$ & $15.6 \%$ \\
\hline $\begin{array}{l}\text { Predicted concentrations within a } \\
\text { factor of 4 of the measured values }\end{array}$ & $53.8 \%$ & $33.2 \%$ & $39.8 \%$ \\
\hline $\begin{array}{l}\text { Predicted concentrations within a } \\
\text { factor of 10 of the measured values }\end{array}$ & $84.2 \%$ & $59.1 \%$ & $61.7 \%$ \\
\hline Variability accounted for by model & $49.3 \%$ & $30.6 \%$ & $33.8 \%$ \\
\hline
\end{tabular}




\section{ALTERNATIVE MODELS}

The third recommendation of the peer review group was to look at alternatives to the Gaussian plume model for estimating concentrations in the vicinity of buildings. Two minimum dilution models were identified as potential alternatives to the Gaussian plume model. Minimum dilution models attempt to provide a lower bound to dilution. When minimum dilution models are used to estimate the concentration, they should estimate an upper bound on the concentration. This is in contrast with typical diffusion models which attempt to estimate the average concentration at a position in the plume.

The first alternative model (Wilson and Chui 1994) predicts maximum concentrations as a function of wind speed, building area, and downwind distance, and the second model (Wilson and Lamb 1994) predicts maximum concentrations as a function of wind speed, wind direction fluctuations, and stretched-string distance. Stretched-string distance is the minimum distance between the release point and receptor without passing through the structure. Both models have a correction term for initial dilution for releases through stacks and vents.

\section{WILSON-CHUI MODEL}

The Wilson-Chui model was developed and tested using wind tunnel data to estimate minimum dilution in plumes released from building vents and short stacks. The model development does not make or depend on a Gaussian assumption. When reformulated to estimate concentrations assuming equal effluent and ambient air densities, the Wilson-Chui model is

$$
(x / Q)_{\max }=\frac{1}{\left(\sqrt{F_{0} D_{0}}+D D\right)^{2}}
$$

where $F_{0}$ is the vent flow in cubic meters per second, $D_{0}$ is an initial dilution, and DD is the downwind dilution. Initial dilution, which is a function of the ratio between the exhaust exit velocity in meters per second and the wind speed, is

$$
D_{0}=1.0+7.0\left(\frac{W_{o}}{U}\right)^{2}
$$

where $\mathrm{W}_{\mathrm{o}}$ is the exhaust velocity. The downwind dilution is given by 


$$
\mathrm{DD}=0.25 \sqrt{\mathrm{UA}}\left(\frac{\mathrm{s}}{\sqrt{\mathrm{A}}}\right)^{0.75}
$$

where $s$ is the "stretched-string" distance in meters between the release point and receptor. The "stretched string" distance is defined as the minimum distance between the two points that accounts for the presence of solid structures.

Maximum concentrations were predicted for each of the 265 concentrations in the building surface data using the Wilson-Chui model to evaluate model performance in the vicinity of full scale structures. The results of the calculations are compared with the observed concentrations in Figure 12. The Wilson-Chui model consistently overpredicts the observed concentrations, as expected. No observed concentrations were higher than the model predictions. Therefore, it is reasonable to conclude that the model provides an upper bound to maximum concentrations in the atmosphere as well as in the wind tunnel.

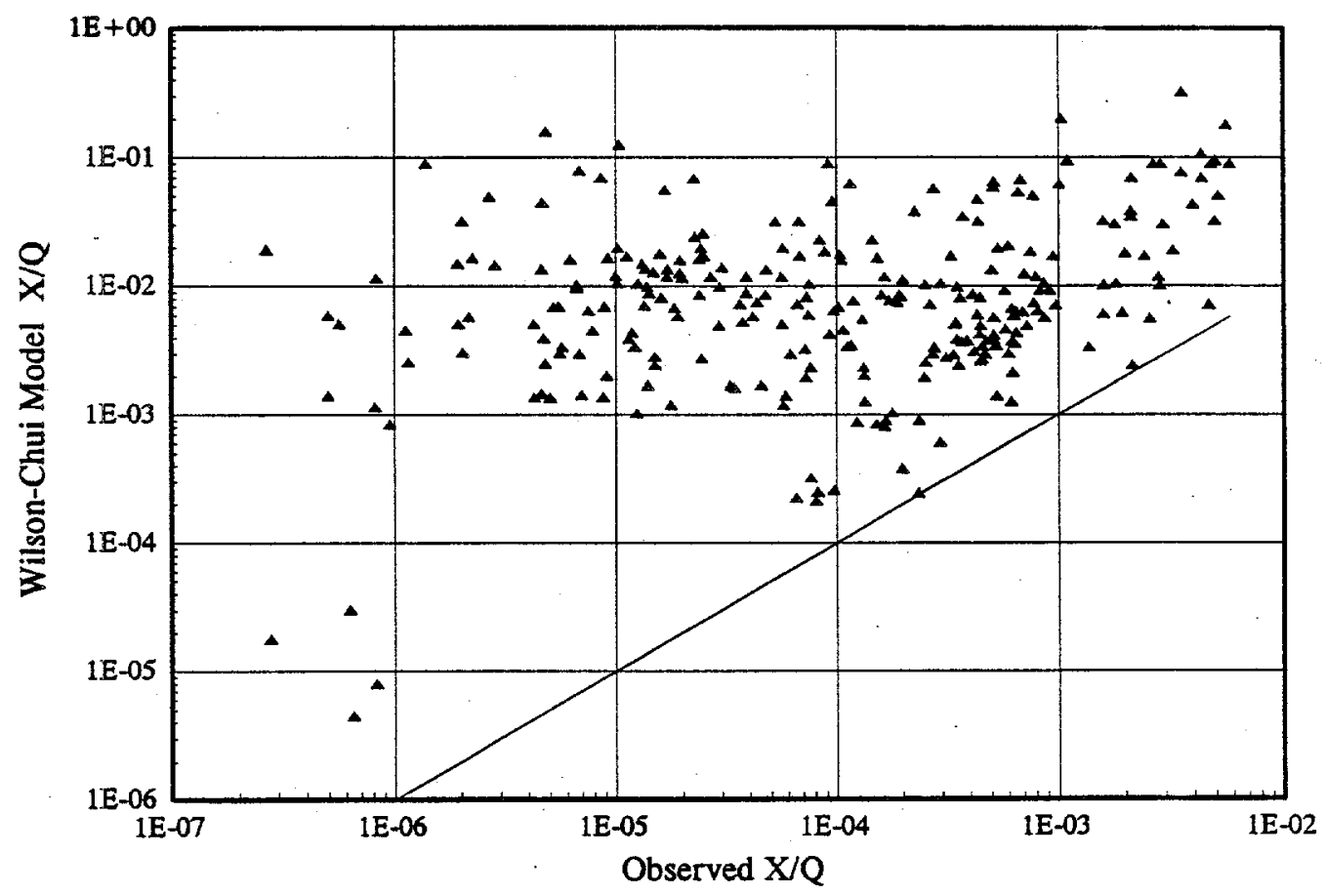

Figure 12. Comparison of Wilson-Chui Model Concentration Predictions with Observed Values 


\section{WILSON-LAMB MODEL}

The Wilson-Lamb model was developed using field data rather than wind tunnel data. The form of the Wilson-Lamb model when reformulated to calculate maximum concentrations is identical to the form of the Wilson-Chui model, i.e., Equation (18). The differences between the models comes in specification of the initial and downwind dilution. In the Wilson-Lamb model initial dilution is defined by

$$
D_{0}=1.0+13.0\left(\frac{W_{0}}{U}\right)
$$

This relationship is taken from Briggs (1975). The downwind dilution is given by

$$
\mathrm{DD}=s \sqrt{\beta \mathrm{U}}
$$

where $\beta$ is a dimensionless parameter related to $\sigma_{\theta}$, the standard deviation of the wind direction fluctuations (in radians), by

$$
\beta=0.039+0.17 \sigma_{\theta}
$$

The constants in this equation were estimated from data collected in the experiments. If $\sigma_{\theta}$ is not available, Wilson and Lamb suggest using the ensemble mean value, $\beta=0.089$. Note that in the Wilson-Lamb model the maximum concentration is not a function of building area.

Maximum concentrations predicted by the Wilson-Lamb model are compared with the measured concentrations in the building surface data set in Figure 13. More than $90 \%$ of the concentration predictions in this data set were made using measured values of $\sigma_{\theta}$ to estimate $\beta$. The relationship between the Wilson-Lamb model predictions and the measured concentrations is similar to that between the Wilson-Chui model predictions and the measured concentrations. The model generally overpredicts the concentrations and provides a reasonable estimate of the maximum concentrations.

\section{COMPARISON OF THE REVISED MODEL WITH THE ALTERNATIVES}

Figures 12 and 13 establish that the two minimum dilution models provide reasonable estimates of maximum concentrations on and adjacent to buildings in the vicinity of a release point. Neither model is a Gaussian plume model. Figure 14 compares concentrations predicted by the revised model with the set of concentrations used to evaluate the minimum dilution models. The pattern of revised 


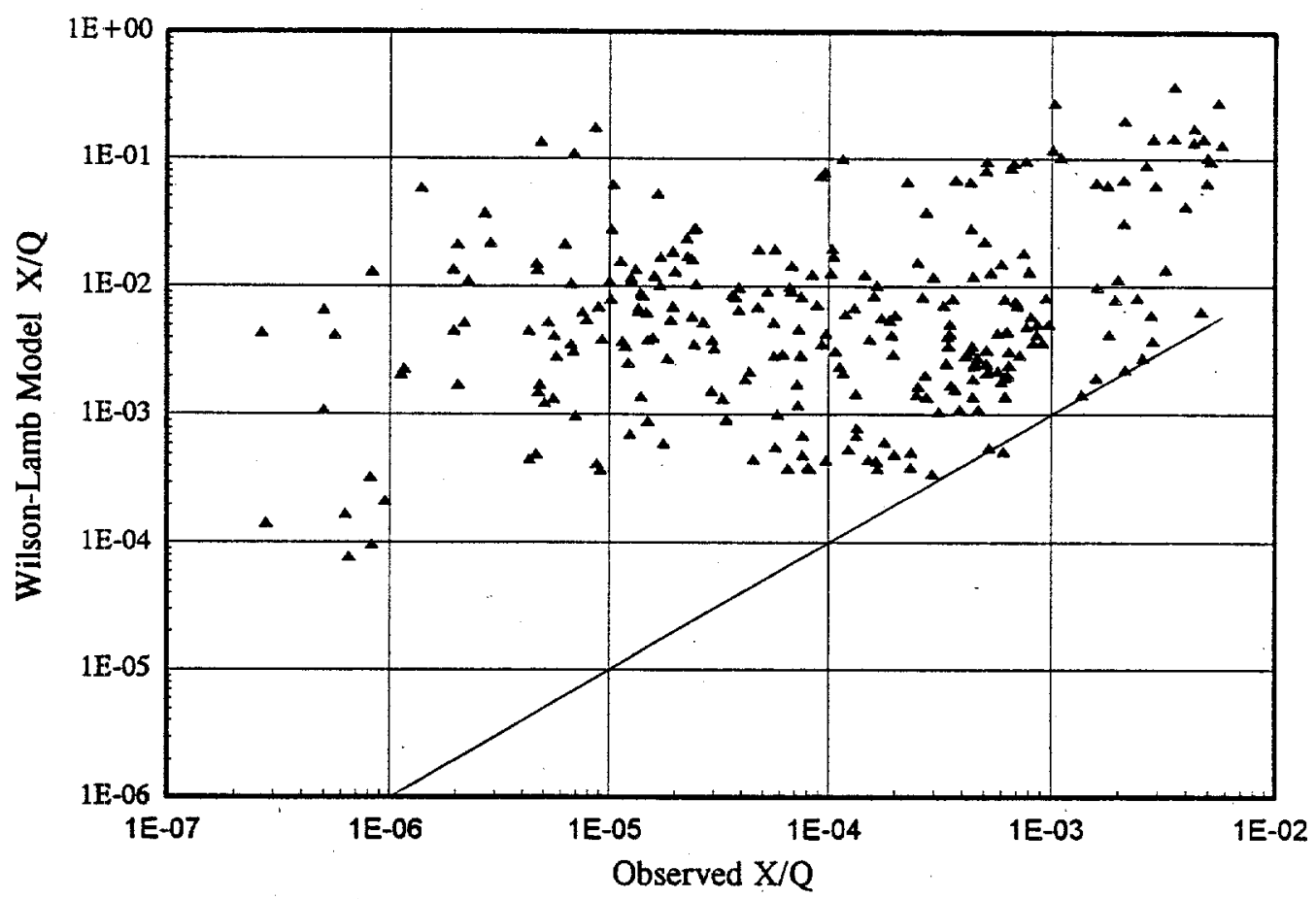

Figure 13. Comparison of Wilson-Lamb Model Concentration Predictions with Observed Values

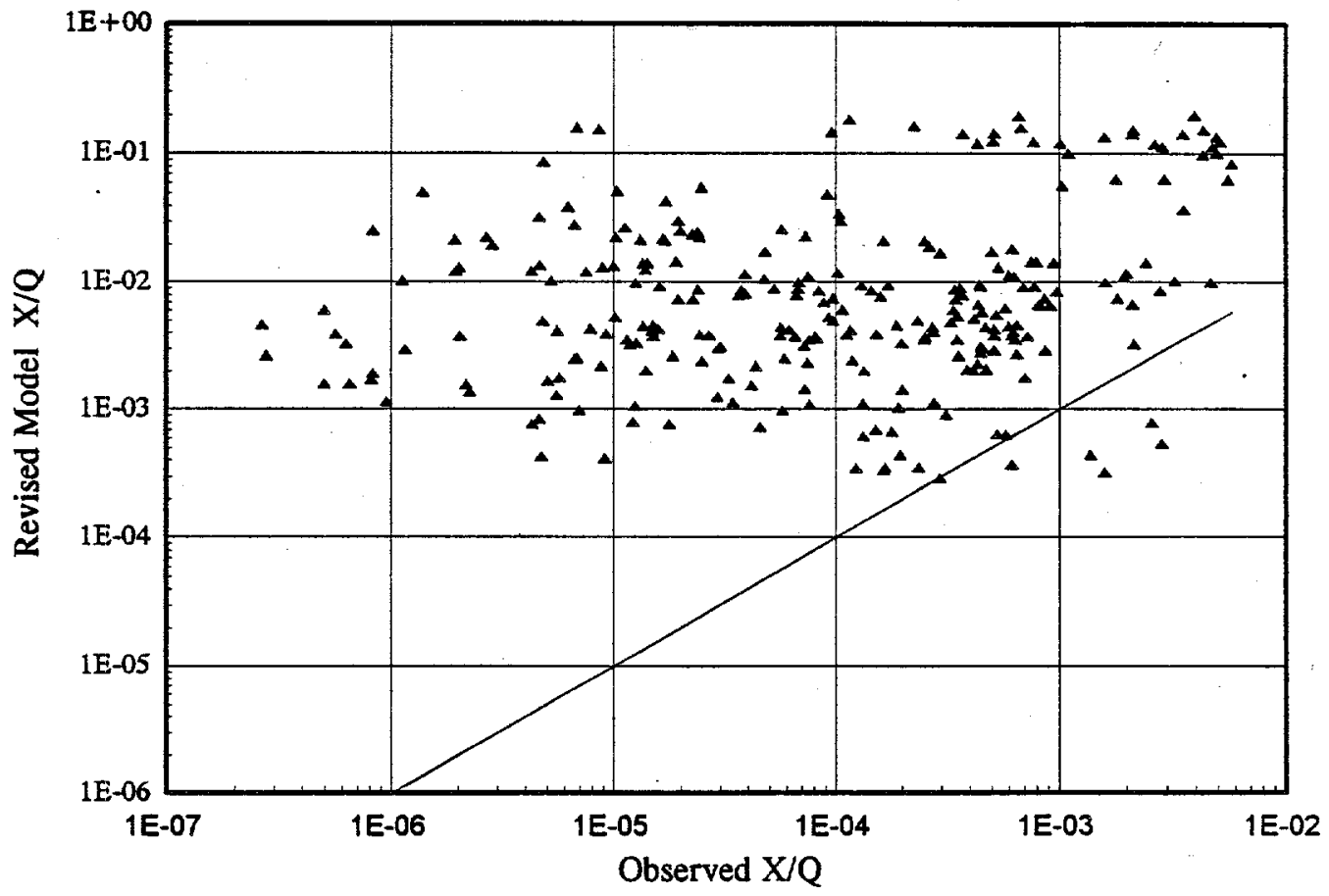

Figure 14. Comparison of Revised Model Concentration Estimates with Observed Values in the Building Surface Data Set 
model predictions is not much different than the pattern for either of the other models. The revised model underpredicts six concentrations, in comparison with no underpredictions by the Wilson-Chui model and one underprediction by the Wilson-Lamb model. However, the revised model should underpredict more frequently than the minimum dilution models because the revised model is designed to predict the average maximum value in a plume rather than the absolute maximum.

Figure 15 compares the predictions of the three models directly. The revised model is most likely to underpredict concentrations. Yet, only about $2.3 \%$ of the concentrations are underpredicted by the revised model, and only $1.5 \%$ are underpredicted by more than a factor of two. With the exception of two concentrations underpredicted by more than a factor of four, cumulative frequency distributions for the revised model and the two alternative models are similar.

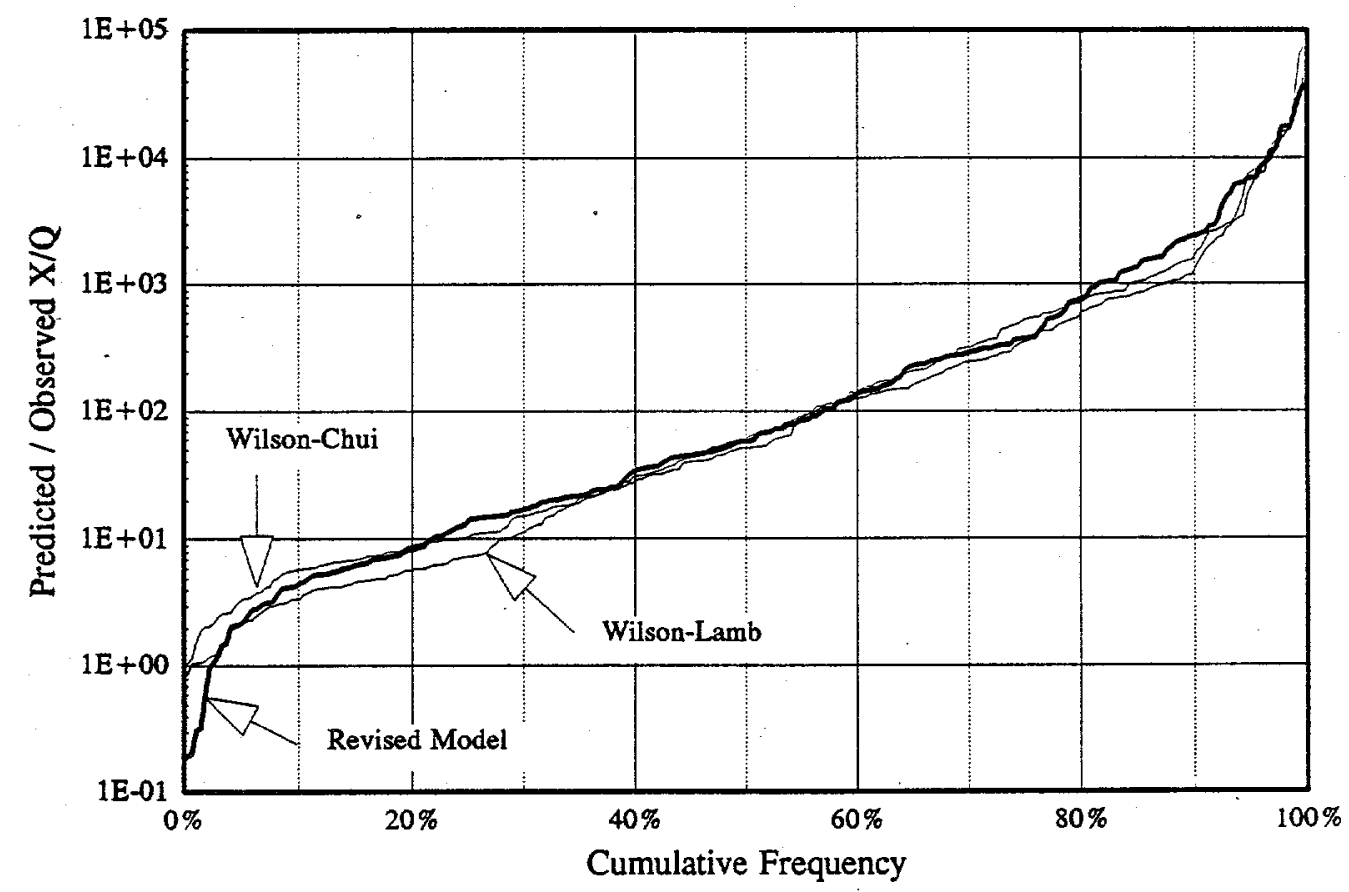

Figure 15. Comparison of Cumulative Frequency Distributions for the Ratios of Predicted to Observed Concentrations for the Wilson-Chui, Wilson-Lamb, and Revised Models 


\section{NEAR-FIELD CONCENTRATION ESTIMATES}

The fourth recommendation of the peer group was to evaluate the revised model with an appropriate subset of the experimental data. Figures 14 and 15 provide a strong indication that the revised model is useful for estimating concentrations on and adjacent to building surfaces, even though the Gaussian model may not be strictly appropriate for this purpose. As a final check, concentrations in the building surface data were combined with concentrations measured near the release point in the ground-level release data set. The resulting data, consisting of 402 concentration measurements, were compared with model predictions as a function of distance from the release point.

Figures 16,17 , and 18 show ratios of the predicted to observed concentrations for the WilsonChui, Wilson-Lamb, and revised model, respectively, as functions of normalized distance. In the case of the ground-level release data, shown by the near-field markers in these figures, the normalized distance is the downwind distance divided by the square root of the building area. In the case of the building-surface data set, the normalized distance is the stretched-string distance divided by the square root of the building area. The ratios shown in the figures indicate that all three models are conservative near the release point because they tend to overestimate concentrations.

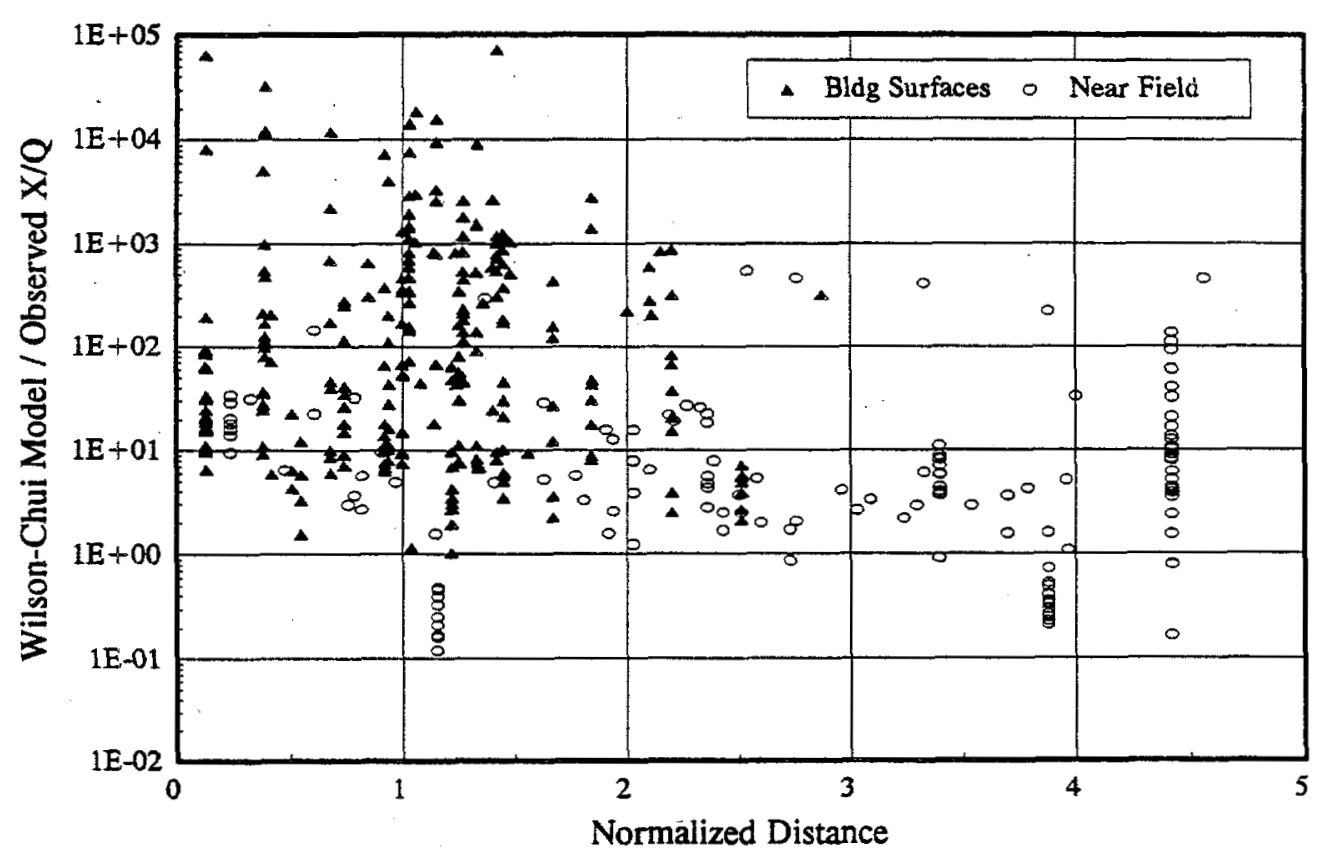

Figure 16. Ratios of Predicted to Observed Concentrations for the Wilson-Chui Model 


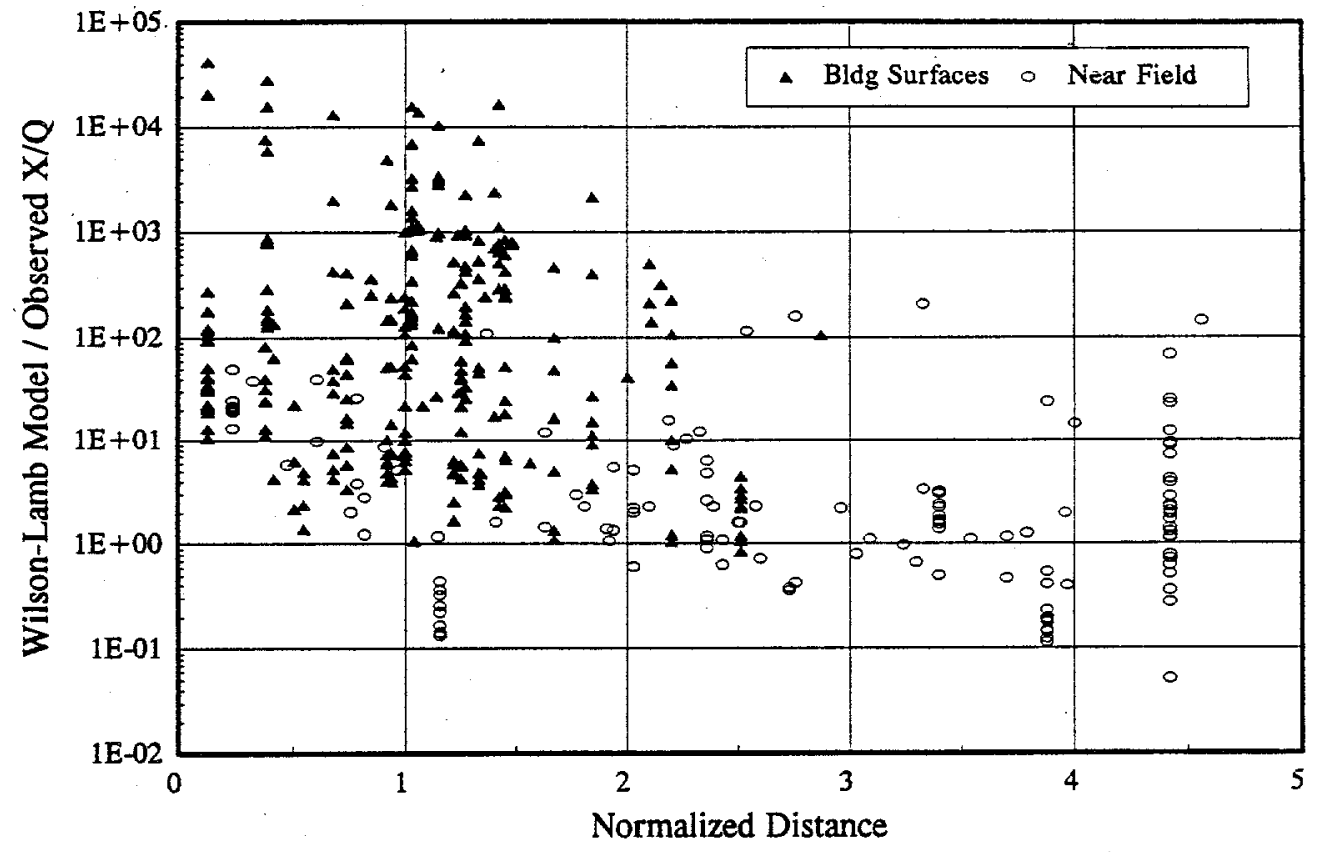

Figure 17. Ratios of Predicted to Observed Concentrations for the Wilson-Lamb Model

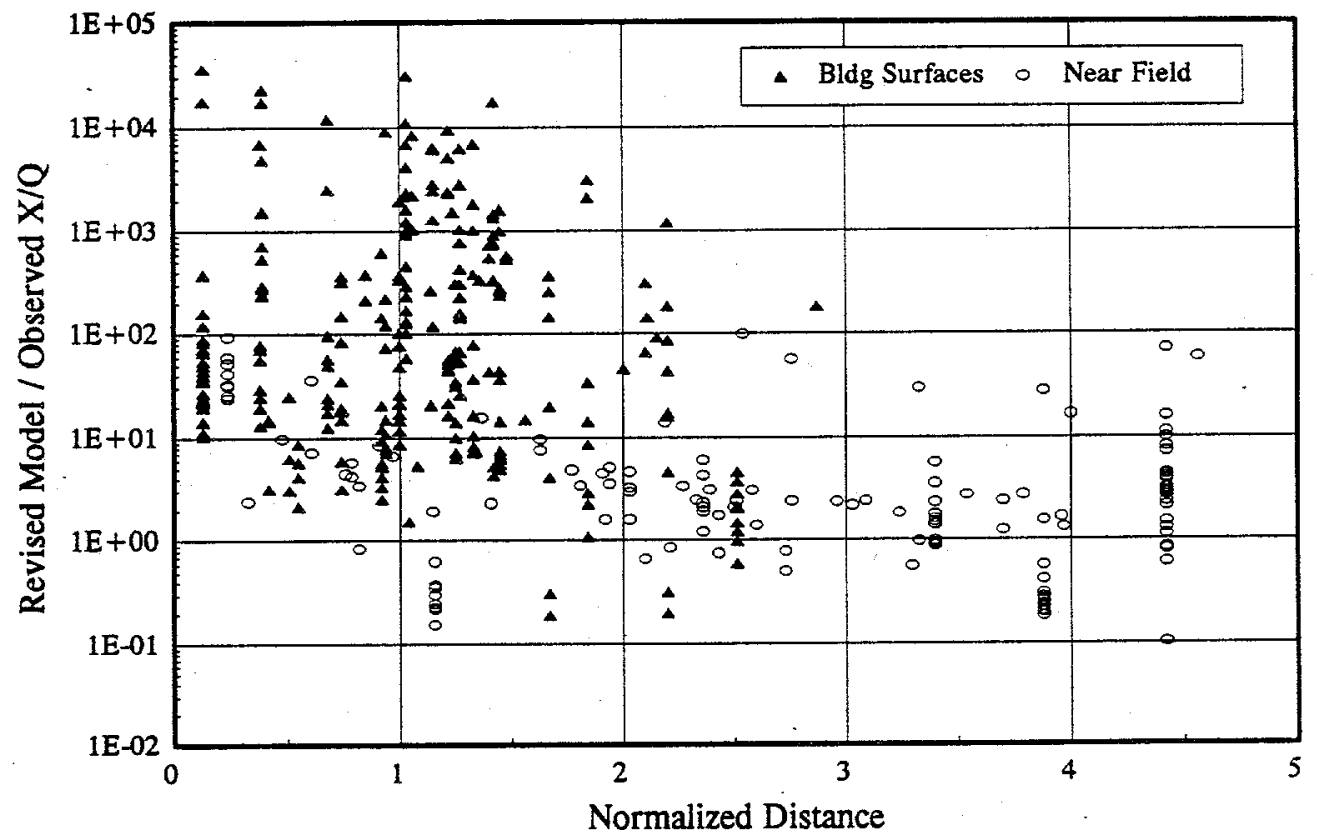

Figure 18. Ratios of Predicted to Observed Concentrations for the Revised Model 
The final comparison between models is a direct comparison of the cumulative frequency distributions in Figure 19. The distributions of ratios from the Wilson-Lamb and revised model are almost identical. This indicates that these two models would give similar results if used in control room habitability assessments. The Wilson-Chui model overpredicts more of the concentrations than either of the other two models. One difference in models that might be responsible for the larger number of overpredictions by the Wilson-Chui model is that the Wilson-Chui model does not have a means of accounting for increased dispersion at low wind speeds due to meander. Both the WilsonLamb model and the revised model account for enhanced dispersion at low wind speeds.

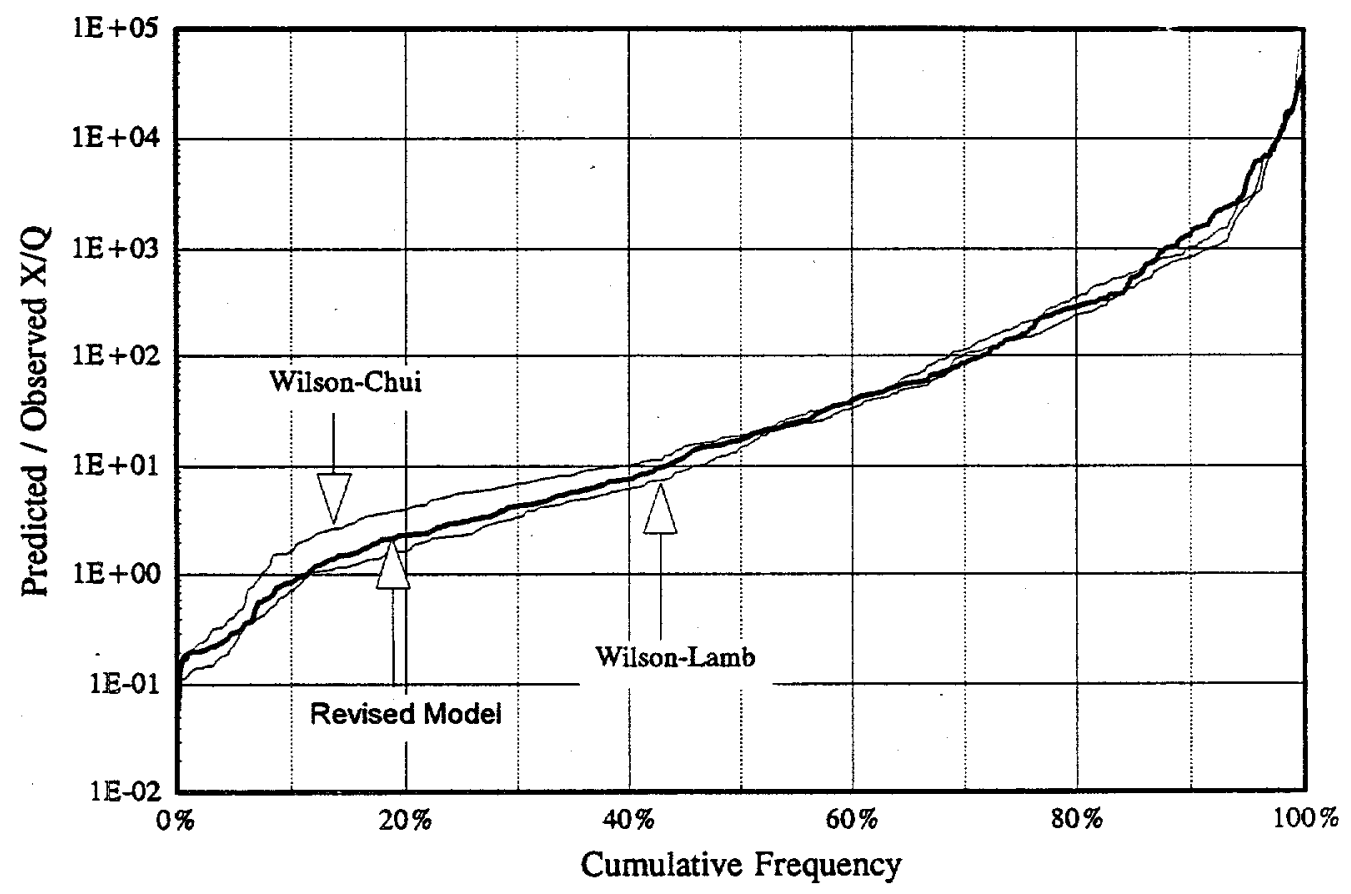

Figure 19. Cumulative Frequency Distributions of the Ratios Between Predicted and Observed Concentrations for the Wilson-Chui, Wilson-Lamb, and Revised Model for All Data 


\section{CONCLUSIONS}

Evaluation of building-wake dispersion models beginning in the mid 1980s has shown that models currently recommended in NRC guidance to licensees tend to significantly overpredict concentrations during low wind speed conditions. As a result, NRC staff felt that the procedures used in evaluation of control room habitability and the consequences of design basis accidents were overly conservative. A new model developed in 1990 for use in predicting concentrations near buildings did not overpredict concentrations at low wind speeds. The 1990 model has recently undergone additional peer review. This report describes the disposition of the primary recommendations of the peer review panel. Those recommendations were

1) The turbulence increment generated by buildings should be assumed to be proportional to the wind speed in accordance with accepted theory and physical reasoning.

2) The effects of meander during low wind speed conditions should be treated explicitly in the model, but the treatment should be separate from the treatment of building wakes.

3) An approach other than straight-line Gaussian models should be considered for determining concentrations when releases are from a building and receptors are on or near the building.

4) Appropriate subsets of the available data should be used to evaluate the model after the suggested changes have been made.

In response to the recommendations, the 1990 model was revised to explicitly treat enhanced atmospheric dispersion in the vicinity of buildings as a combination of the effects of low and high wind speed phenomena. The low wind speed component of the enhanced dispersion in the revised model decreases with increasing wind speed. In contrast, the high wind speed component increases with increasing wind speed. Turbulence data have been used to estimate model parameters related to the increase of turbulence responsible for enhanced dispersion at low and high wind speeds.

Diffusion data collected in experiments at seven reactors indicate that the revised model is a significant improvement over the building-wake models recommended in existing NRC guidance to licensees.

Two alternative, non-Gaussian models developed to estimate minimum dilution (maximum concentrations) in plumes from building stacks and vents were identified and tested using a second set of data from experiments at three of the reactors. These models appear to predict an upper bound for concentrations in the immediate vicinity of the release point. Concentrations predicted by the revised 
model for the same data also tend to be higher than the measured values. The differences between the predictions of the minimum dilution models and those of the revised model fall within the range of differences that is to be expected given the intended bias of the minimum dilution models. Further comparison of the revised model with the minimum dilution model indicates that all of the models tend to be conservative near the release point and become less conservative as the distance from the release point increases. Cumulative frequency distribution of the ratios of predicted to observed concentrations for the revised model is nearly identical to the distribution for the Wilson-Lamb minimum dilution model.

The revised model incorporates the changes recommended by the peer review panel and concentration predictions near release points that are comparable to the concentrations predicted by minimum dilution models. Therefore, the revised model is considered to be appropriate for use in estimating concentrations for control room habitability assessments. The revised model is also considered to be appropriate for use in estimating concentrations in the near field for use in evaluating the consequences of design basis accidents. 


\section{REFERENCES}

Bander, T. J. 1982. PAVAN: An Atmospheric Dispersion Program for Evaluating Design Basis Accidental Releases of Radioactive Materials from Nuclear Power Stations. NUREG/CR-2858, U.S. Nuclear Regulatory Commission, Washington, D.C.

Briggs, G. A. 1975. "Plume Rise Predictions." in Lectures on Air Pollution and Environmental Impact Analyses. American Meteorological Society, Boston, Massachusetts. pp. 59-111.

Briggs, G. A., A. H. Huber, W. H. Snyder, and R. S. Thompson. 1992. "Discussion." Atmospheric Environment 26B(4):513-517.

Dickson, C. R., G. E. Start, and E. H. Markee. 1969. "Aerodynamic Effects of the EBR-II Reactor Complex on Effluent Concentration." Nuclear Safety 10:228-242.

Draxler; R. R. 1976. "Determination of Atmospheric Diffusión Parameters." Atmospheric Environment 10:99-105.

Frenkiel, F. N. 1953. "Turbulent Diffusion: Mean Concentration Distribution in a Flow Field of Homogeneous Turbulence." Advances in Applied Mechanics 3:61-107.

Gifford, F. A. 1976. "Turbulent Diffusion Typing Schemes - A Review." Nuclear Safety 17(1): 68-86.

GPUSC. 1972. "Atmospheric Diffusion Experiments with $\mathrm{SF}_{6}$ Tracer Gas at Three Mile Island Nuclear Station under Low Wind Speed Inversion Conditions." Amendment \#24, Docket No. 50289, General Public Utilities Service Corporation.

Islitzer, N. F. 1965. Aerodynamic Effects of Large Reactor Complexes upon Atmospheric Turbulence and Diffusion. IDO-12041, Idaho Operations Office, U.S. Atomic Energy Commission, Idaho Falls, Idaho.

Kao, S. K. 1984. "Theories of Atmospheric Transport and Diffusion." In Atmospheric Science and Power Production. DOE/TIC-27601, D. Randerson, ed. U.S. Department of Energy, Washington, D.C. pp. 189-239.

Martin, D. O. and J. A. Tikvart. 1968. "A General Atmospheric Dispersion Model for Estimating the Effects on Air Quality of One or More Source." Presented at the 61st Annual Meeting of the Air Pollution Control Association, St. Paul, Minnesota, 18p.

Murphy, K. G. and K. M. Campe. 1974. "Nuclear Power Plant Control Room Ventilation System Design for Meeting General Design Criterion 19." In Proceedings of the 13th AEC Air Cleaning Conference, San Francisco, California, CONF-740807, U.S. Atomic Energy Commission, Washington, D.C. 
Ogawa, Y. and S. Oikawa. 1982. "A Field Investigation of the Flow and Diffusion Around a Model Cube." Atmospheric Environment 16(2):207-222.

Ramsdell, J. V. 1988. Atmospheric Diffusion for Control Room Habitability Assessments. NUREG/CR-5055, U.S. Nuclear Regulatory Commission, Washington, D.C.

Ramsdell, J. V. 1990. "Diffusion in Building Wakes for Ground-Level Releases." Atmospheric Environment. 24B(3):377-388.

Sagendorf, J. F. and C. R. Dickson. 1974. Diffusion Under Low Windspeed Inversion Conditions. NOAA TM ERL ARL-52, Air Resources Laboratory, Idaho Falls, Idaho.

Sagendorf, J. F., J. T. Goll, and W. F. Sandusky. 1982. XOQDOQ: Computer Program for the Meteorological Evaluation of Routine Effluent Releases at Nuclear Power Stations. NUREG/CR4380, U.S. Nuclear Regulatory Commission, Washington, D.C.

Start, G. E., J. F. Cate, C. R. Dickson, N. R. Ricks, G. R. Ackerman, and J. F. Sagendorf. 1978. Rancho Seco Building Wake Effects on Atmospheric Diffusion. NUREG/CR-0456, U.S. Nuclear Regulatory Commission, Washington, D.C.

Start, G. E., N. F. Hukari, J. F. Sagendorf, J. H. Cate, and C. R. Dickson. 1980. EOCR Building Wake Effects on Atmospheric Diffusion. NOAA Technical Memorandum ERL ARL-91, Air Resources Laboratory, Silver Springs, Maryland.

Tadmor, J. and Y. Gur. 1969. "Analytical Expressions for Vertical and Lateral Dispersion Coefficients in Atmospheric Diffusion." Atmospheric Environment 3:688-689.

Tennekes, H. and J. L. Lumley. 1972. A First Course in Turbulence. The MIT Press, Cambridge, Massachusetts.

Thuillier, R. H. and R. M. Mancuso. 1980. Building Effects on Effluent Dispersion from Roof Vents at Nuclear Power Plants. EPRI NP-1380, Electric Power Research Institute, Palo Alto, California.

Thuillier, R. H. 1982. "Dispersion Characteristics in the Lee of Complex Structures." Journal of the Air Pollution Control Association 32:526-532.

Thuillier, R. H. 1992. "Evaluation of a Puff Dispersion Model for Use in Complex Terrain." Journal of the Air Pollution Control Association 42(3):290-297.

U.S. Nuclear Regulator Commission (NRC). 1972. On-Site Meteorological Programs. Regulatory Guide 1.23 (formerly AEC Safety Guide 23). U.S. Nuclear Regulatory Commission, Washington, D.C.

U.S. Nuclear Regulator Commission (NRC). 1982. Atmospheric Dispersion Models for Potential Accidental Consequence Assessments at Nuclear Power Plants. Regulatory Guide 1.145, Revision 1. U.S. Nuclear Regulatory Commission, Washington, D.C. 
U.S. Nuclear Regulator Commission (NRC). 1987. "Control Room Habitability System." Standard Review Plan for the Review of Safety Analysis Reports for Nuclear Power Plants. NUREG-0800. U.S. Nuclear Regulatory Commission, Washington, D.C.

Wilson, D. J. and E. H. Chui. 1994. "Influence of Building Size on Rooftop Dispersion of Exhaust Gas." Atmospheric Environment 28(14):2325-2334.

Wilson, D. J. and B. J. Lamb. 1994. "Dispersion of Exhaust Gases from Roof Level Stacks and Vents on a Laboratory Building." Atmospheric Environment. 28(19):3099-3111. 
APPENDIX A

PEER REVIEW PANEL 


\title{
PEER REVIEW PANEL
}

R. P. Hosker

NOAA/ATDD

456 S. Illinois Ave

Oak Ridge, TN 37830

\author{
A. H. Huber \\ USEPA/AREAL \\ MD-56 \\ Research Triangle Park, NC 27711
}

William B. Petersen

USEPA/AMRB

MD-80

Research Triangle Park, NC 27711

J. F. Sagendorf

NOAA/ARL

1750 Foote Drive

Idaho Falls, ID 83402

I. Spickler

A-424

U.S. Department of Energy

Washington, DC 20545 


\section{APPENDIX B}

DRAFT REPORT REVIEW COMMENTS 


\section{APPENDIX B}

\begin{tabular}{|c|c|c|c|}
\hline Reviewer & Section & Comment & Resolution \\
\hline $\begin{array}{l}\text { J. F. Sagendorf } \\
\text { NOAA, Air Resources } \\
\text { Laboratory }\end{array}$ & . & Letter attached. & \\
\hline \multirow[t]{7}{*}{$\begin{array}{l}\text { R. P Hosker } \\
\text { NOAA, Atmospheric } \\
\text { Transport and Diffusion } \\
\text { Division }\end{array}$} & 1990 Model & $\begin{array}{l}\text { related to Eq. (4), } k \text { is not the best } \\
\text { choice of symbols }\end{array}$ & $\begin{array}{l}\text { Replaced the } k \text { with } r_{v} \text { and } r_{w} \text { to indicate } \\
\text { that the constants are average Lagrangian } \\
\text { correlations coefficients for } v \text { and } w \text {, } \\
\text { respectively. }\end{array}$ \\
\hline & $\begin{array}{l}\text { General Form for } \\
\text { Diffusion } \\
\text { Increments }\end{array}$ & $\begin{array}{l}\text { Different } k \text { than in Eq. (4)? Same } \\
\text { as comment relative to use of } k \text { as } \\
\text { above. }\end{array}$ & See above. \\
\hline & $\begin{array}{l}\text { Low Wind Speed } \\
\text { Increment }\end{array}$ & $\begin{array}{l}\text { Not clear that choice of time scale } \\
\text { of } 1000 \mathrm{~s} \text { is appropriate. Elaborate. }\end{array}$ & $\begin{array}{l}\text { Added discussion to text. Model is not } \\
\text { sensitive to changes in time scales. }\end{array}$ \\
\hline & & $\begin{array}{l}\text { Can't decide if low wind speed, } \\
\text { vertical turbulence increment of zero } \\
\text { for neutral and unstable conditions } \\
\text { is realistic. Argue for. it. }\end{array}$ & $\begin{array}{l}\text { Changed assumption to use the } 100 \mathrm{~s} \\
\text { time scale for neutral and unstable } \\
\text { conditions. This is probably an } \\
\text { underestimate for unstable conditions. }\end{array}$ \\
\hline & $\begin{array}{l}\text { High Wind Speed } \\
\text { Increment }\end{array}$ & $\begin{array}{l}\text { related to Fig. 1. How much does } \\
\text { correlation improve if the data point } \\
\text { from Dickson, et al., showing an } \\
\text { increase of about } 2.5 \text { in sigma v for } \\
\text { a wind speed of about } 6 \mathrm{~m} / \mathrm{s} \text { is } \\
\text { dropped? Any rationale to discard } \\
\text { it? }\end{array}$ & $\begin{array}{l}\text { If the point is dropped, the correlation } \\
\text { increases from } 0.73 \text { to } 0.79 \text {. However, } \\
\text { there is no basis in the data set that could } \\
\text { be used to support deleting the point. }\end{array}$ \\
\hline & & Why assume $\Delta \sigma_{\mathrm{vl}}=\Delta \sigma_{\mathrm{w} 1}$ ? & $\begin{array}{l}\text { The assumption has been dropped. } \Delta \sigma_{\mathrm{v} 1} \\
\text { and } \Delta \sigma_{\mathrm{w} 1} \text { have been estimated from } \\
\text { turbulence measurements. }\end{array}$ \\
\hline & & $\begin{array}{l}\text { Is the weighting function chosen to } \\
\text { favor conservatism? }\end{array}$ & $\begin{array}{l}\text { Yes. A statement to this effect is } \\
\text { included in the text. }\end{array}$ \\
\hline $\begin{array}{l}\text { A. H. Huber } \\
\text { U.S. Environmental } \\
\text { Protection Agency, } \\
\text { AREAL }\end{array}$ & & No response to draft report. & \\
\hline $\begin{array}{l}\text { W. B. Petersen } \\
\text { U. S. Environmental } \\
\text { Protection Agency } \\
\text { AMRB }\end{array}$ & & No response to draft report. & \\
\hline $\begin{array}{l}\text { I. Spickler } \\
\text { U.S. Department of } \\
\text { Energy }\end{array}$ & & No response to draft report. & \\
\hline $\begin{array}{l}\text { F. A. Gifford } \\
109 \text { Gorgas Lane } \\
\text { Oak Ridge, TN }\end{array}$ & & Letter attached. & \\
\hline
\end{tabular}

B. 1 


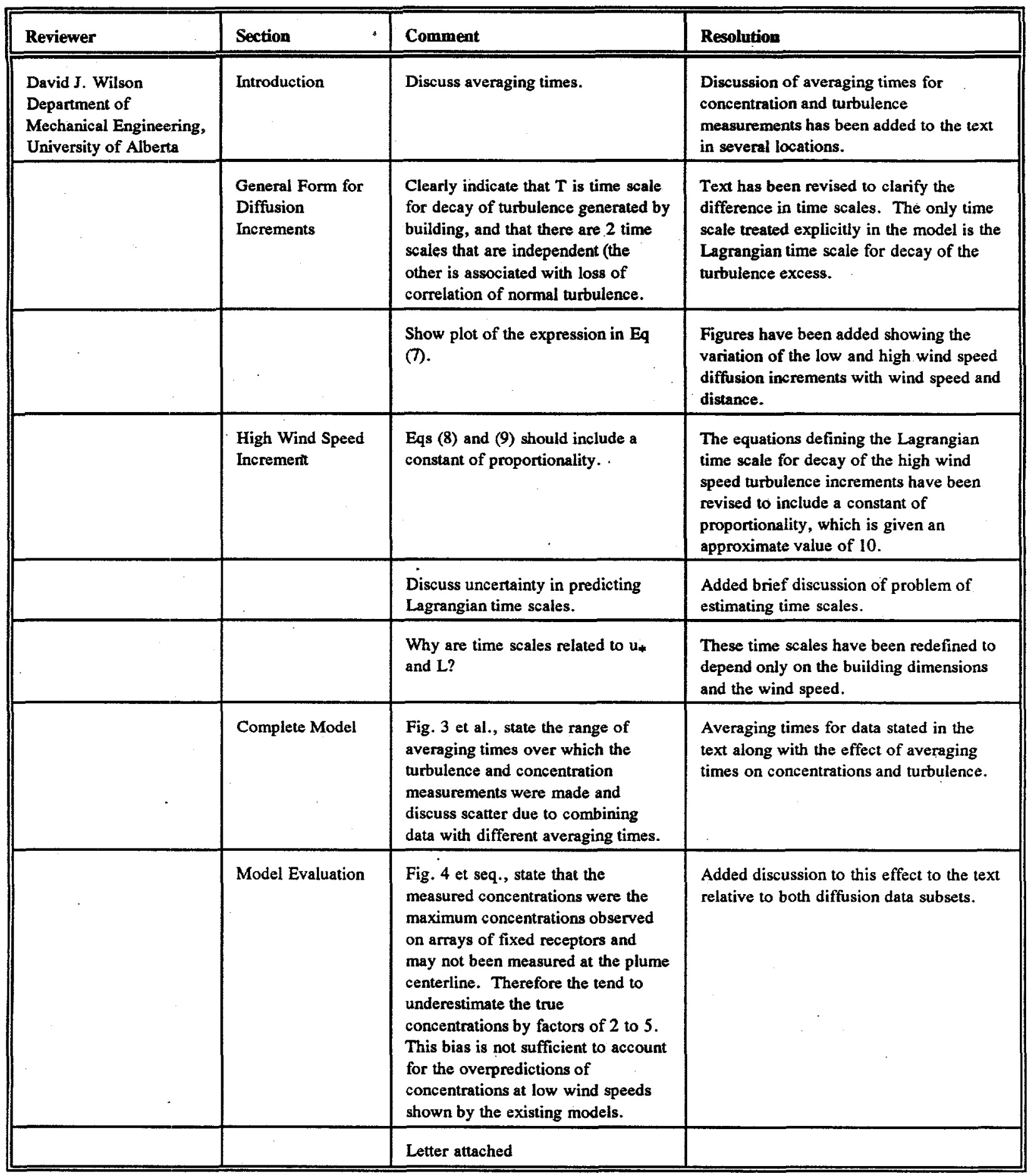




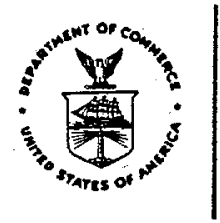

September 23, 1994

J. V. Ramsdell, Jr

Battelle

Pacific Northwest Laboratories

Battelle Boulevard

P.O. Box 999

Richland, Washington 99352

Dear Mr. Ramsdell:

I read the letter report "Dispersion Estimates in the Vicinity of Buildings" describing the revisions to the building wake diffusion model. The model appears to greatly reduce the overprediction associated with regulatory modeling of diffusion near buildings without increasing the risk of underpredicting concentrations. I have no problems with accepting this as a reasonable approach to the problem. I also feel that the Wilson-Chui and Wilson-Lamb models might be very useful in establishing an upper bound to the possible concentrations near buildings.

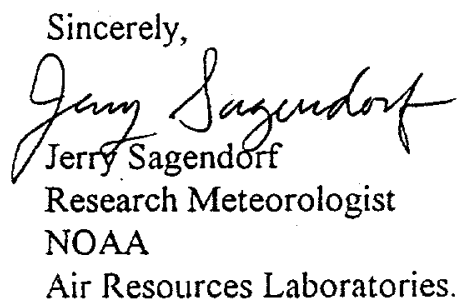

75 Years Stimulating America's Progress $\star 1913-1988$

B.3

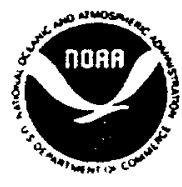


F. A. Gifford

109 Gorgas Lane

Oak Ridge, TN 37830

(615) $482-1819$

August 27,1994

J. V. Ramsdell

Battelle PNW Labs.

PO Box 999

Richland, Washington 99352

Dear Van,

I read your report on revised dispersion estimates in the vicinity of buildings and can only say that the revision you propose seem reasonable enough to me. Certainly the improved agreement with all the existing data is a strong point in its favor. It seems to meet the various criticisms that were made of the original model. I've felt that more consideration of this problem was needed since the simpleminded suggestion I made (over 30 years ago) was adopted into the regulatory models, and am delighted that you are working on the problem.

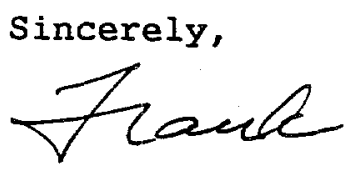

Frank Gifford. 


\author{
Dr. J.V. Ramsdell \\ Earth and Environmental Science Center \\ Battelle Pacific Northwest Labs \\ P.O. Box 999 \\ Richland, Washington 99352 \\ U.S.A.
}

Dear Dr. Ramsdell:

\title{
SUBJECT: Comments on "Dispersion Estimates in the Vicinity of Buildings"
}

In your letter of August 23, you asked me for written comments on your proposed model for dispersion near buildings. I did not subject the model to any rigorous review, but recorded my general impressions, summarized in point form below:

- I agree with your general approach that uses a windspeed-independent increment to the crosswind and vertical turbulence velocity variances. This idea is consistent with several sets of observations showing that the vertical and crosswind velocity components approach a non-zero limit as windspeed goes to zero. This is the major feature of your model that reduces the large overpredictions (at low windspeed) shown in Figure 4 to much smaller values shown in Figure 6.

- Your model for the decaying turbulence in building wakes needs more explanation and elaboration. You should refer directly to Ramsdell (1990), and also give some physical explanation for your choice of equation (6) and plot the functional form of equation ( 7 ) on a figure. It should be made clear to the reader that $T$ is the Lagrangian timescale of crosswind turbulence generated by the building. You should multiply the right hand side of equations (8) and ( 9 ) by a constant of proportionality, and then give a brief discussion of the large uncertainty that exists in predicting Lagrangian timescales.

- I find it difficult to understand how the Lagrangian timescale of buildinggenerated turbulence should be characterized by atmospheric values of friction velocity $u_{*}$ and Monin-Obukhov length $L$. Explain and justify. 
- You make the implicit assumption that atmospheric turbulence and buildinggenerated turbulence variances add as random uncorrelated variables. If these turbulence fields are uncorrelated, how can the atmospheric values be used to characterize building turbulence in equations (8) and (9)?

- You should state the range of averaging times over which the turbulence and concentration values were measured in the various experiments that contributed to each of the figures. Close to a small source, averaging time can have a significant effect on mean concentration. How much of the scatter in the data can be attributed to combining experiments for varying averaging times? (I expect this will be a small effect but you should address it!)

- You should state that the measured values of concentration were the maximum concentrations observed at an array of fixec receptors for a given downwind distance. Because the plume centerline may not have fallen directly on one of the receptors, the measured concentrations will tend to underestimate the actual plume centerline concentrations predicted by models. I would guess that this could cause the measured concentrations to underpredict the true centerline concentration by factors of two to five. However, the existing models (including mine) overpredict concentration at low windspeeds by factors of 10 to 1000 , suggesting that the measurement uncertainties are not the cause of existing model overpredictions. You need to make this point.

I hope these comments are helpful, and I take some comfort from the observation that the Wilson-Lamb model produces predicted-to-observed concentration ratios close to your revised model over $90 \%$ of the observed conditions. In summary, I support your use of a zerowindspeed turbulence increment, but am rather uncomfortable with the functional forms used for building-generated Lagrangian timescale $\mathrm{T}$.

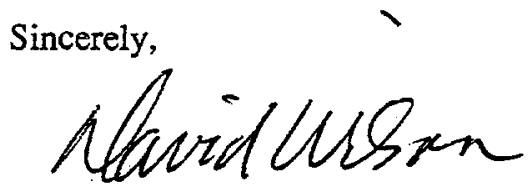

David J. Wilson

DJW:ga 


\section{Distribution}

No. of

Copies

\section{OFFSITE}

12 DOE Office of Scientific and Technical Information

15 Division of Radiation Safety and Safeguards

Office of Nuclear Reactor Regulation U.S. Nuclear Regulatory Commission Washington, D.C. 20555

T. H. Essig

A. M. Gill

J. C. Hayes

J. Y. Lee (12)

1 Standardization Project Directorate Office of Nuclear Reactor Regulation U.S. Nuclear Regulatory Commission Washington, D.C. 20555

\section{B. Zalcman}

3 Division of Reactor Accident Analysis Office of Nuclear Regulatory Research U.S. Nuclear Regulatory Commission Washington, D.C. 20555

C. M. Ferrell

G. R. Mazetis

J. H. Schaperow
No. of

Copies

1 Division of Regulatory Applications Office of Nuclear Regulatory Research U.S. Nuclear Regulatory Commission Washington, D.C. 20555
A. K. Roecklein

\section{ONSITE}

\section{Pacific Northwest Laboratory}

K. J. Allwine

K9-30

J. G. Droppo

K6-55

C. J. Fosmire

K9-30

P. C. Hays

A. H. McMakin

K6-62

B. A. Napier

J. V. Ramsdell (20)

S. A. Stage

K6-62

K3-54

K9-30

Records Center (2)

K9-30

Publishing Coordination

Technical Library (5) 